
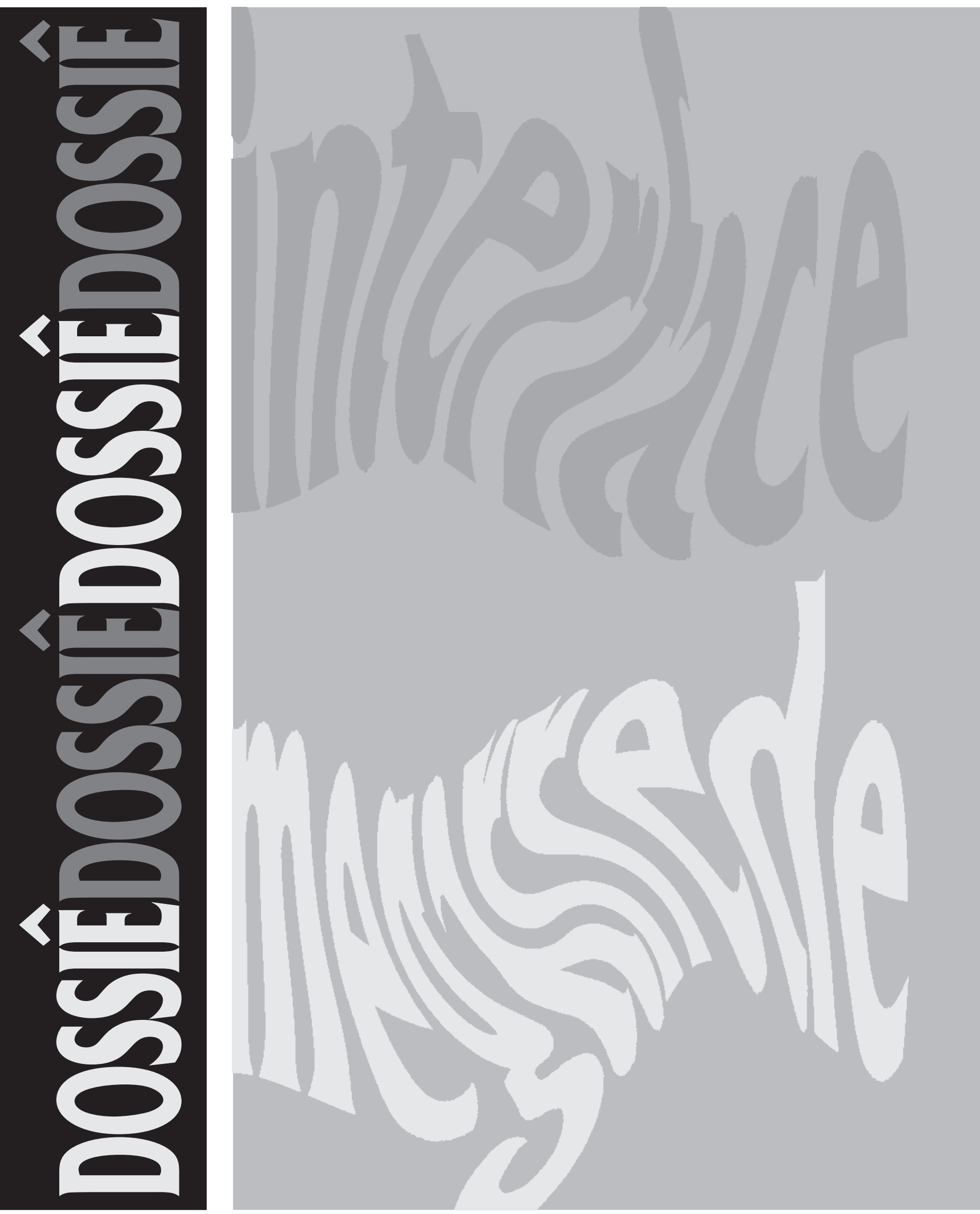
ARNALDO

MANDEL é professor

do Instituto de

Matemática e

Estatística da USP.

e-mail: am@ime.usp.br

\section{IMRE SIMON}

é presidente da

Comissão Central de

Informática da USP.

e-mail: is@ime.usp.br

\section{JORGE L. DELYRA}

é professor

do Instituto de

Física da USP.

e-mail:

delyra@fma.if.usp.br

Este trabalho foi substancialmente enriquecido por inúmeras observações e contribuições que os autores receberam de Eduardo Bonilha de Toledo Leite, Hartmut Richard Glaser, Istvan Simon, Janos Simon, Jean-Eric Pin, Marília Junqueira Caldas, Martin Grossmann, Nicolau Reinhard Demi Getschko, Siang Wun Song e Tomasz Kowaltowski. Os autores agradecem efusivamente essas contribuições.

Uma versão preliminar deste do cumento serviu de base para um debate no simpósio "A Importância da Ciência para o Desenvolvimento Nacional", organizado pela Academia Brasileira de Ciências, dentro das comemorações dos seus 80 anos de existência. O simpósio foi realizado de 5 a 7 de março de 1997, na Universidade de São Paulo. Os debatedores foram os acadêmicos Carlos losé Pereira de Lucena, Clovis Gonzaga e José Ellis Ripper Filho.

Este trabalho está sendo reimpresso com a autorização da Academia Brasileira de Ciências. 


\section{I.INTRODUÇÃO}

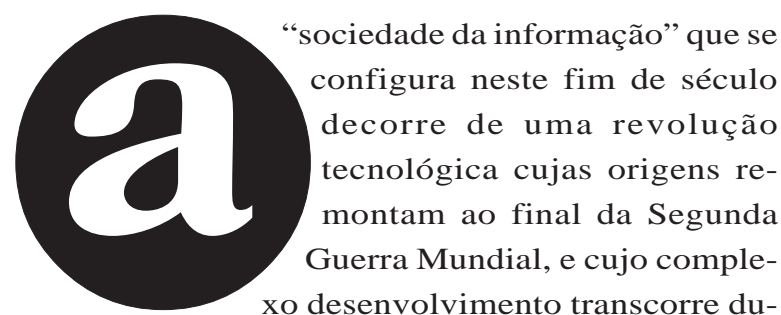
rante toda a segunda metade do século, com potencial para modificar, a médio prazo, muitos aspectos da vida cotidiana. Segundo a National Science Foundation, a tecnologia eletrônica da informação alterará cada instituição da vida americana, com "efeito transformador", até 1998. Embora muitos elementos tenham contribuído para essa transformação, dois pontos focais aparecem como determinantes do seu crescimento: computação e comunicação, diretamente ligados a dois objetos tecnológicos que proporcionaram a esse crescimento uma velocidade nunca vista: microcomputador e rede Internet.

Dessa forma, nos últimos anos praticamente todo cidadão tem testemunhado uma invasão crescente do seu cotidiano por novas tecnologias de computação e de comunicação que causam mudanças dramáticas no papel, na quantidade, na qualidade e na velocidade de troca de informação com que ele lida no dia-a-dia.

Essa invasão é alardeada pelos meios de comunicação de massa: há anos que temos cadernos de informática semanais nos maiores jornais diários do país, há anos que a Gazeta Mercantil mantém uma seção diária sobre informática e telecomunicações, há anos que o computador, as comunicações, as redes de computadores, especialmente a Internet e a teia mundial (World Wide Web) vêm ocupando espaços crescentes nas grandes revistas semanais internacionais e nacionais. Gostaríamos de realçar aqui a cobertura da revista The Economist que aborda regulamente alguns dos temas mais palpitantes da área, de forma não técnica, mas sempre com grande profundidade e grande originalidade (1). Ademais, há alguns meses, endereços eletrônicos de $e$-mail ou de páginas na teia rotineiramente fazem parte de anúncios em todos os meios de comunicação, até mesmo no Brasil, inclusive na televisão.

Presenciamos também uma enxurrada de livros sobre informática, sobre computadores, sobre a teia mundial, sobre trabalho em grupo, sobre ensino a distância, sobre a Internet, sobre as Intranets, sobre Linux, Windows, Netscape, Java e tantos outros assuntos denotados por palavras que foram entrando no nosso vocabulário a partir dos primeiros anos da década de 1990 e que cada vez mais rapidamente vêm adquirindo adeptos em grandes números, forçados ou não a aderir. É impressionante o grande volume de traduções e textos originais em português, sem similar em outra área de atividade.

Os jovens são um vetor irresistível e inexorável da inovação. Tudo indica que para eles não haverá uma transição brusca para a "sociedade da informação", tudo que terão de fazer é ir se adaptando à medida que surgirem novas ondas de conceitos, técnicas e produtos.

As novidades afetam um número cada vez maior de aspectos da vida profissional e cotidiana: editoração eletrônica, compras a distância, jogos e diversão via computador, telefone pela Internet, correio eletrônico, navegação pela teia mundial, televisão sob demanda espreitando na esquina, distribuição e aquisição de software, busca e obtenção instantânea de informações de qualquer tipo.

Fala-se, também, de novas tecnologias que terão o potencial para impactar algumas das instituições mais sólidas em que nossa civilização é baseada com a introdução do ensino a distância, telemedicina, biblioteca digital e dinheiro eletrônico, por exemplo.

O uso da rede aumenta dramaticamente o grau de cooperação entre parceiros, muitas vezes geograficamente distantes, e impõe novos paradigmas, novas possibilidades e novos problemas para muitas atividades. A rede está rapidamente entrando nas residências; nos EUA 15\% da população já tem acesso residencial à Internet (2).

Entendemos que o fenômeno descrito 
baseia-se numa verdadeira revolução nas formas e métodos como a informação é gerada, armazenada, processada e transmitida. Essa revolução está sendo permitida pela convergência de extraordinários avanços nas tecnologias de computação e de comunicação, justificando o nosso título. Uma de suas características mais marcantes é a velocidade explosiva com a qual ela se processa (3).

O objetivo deste documento é fazer uma reflexão sobre esses acontecimentos e tentar isolar alguns dos aspectos mais marcantes em que os mesmos se baseiam, evitando uma abordagem demasiadamente técnica. Procuraremos mostrar também a história da evolução destas tecnologias bem como alguns dos seus aspectos em estudo ou em desenvolvimento no momento, que têm alta probabilidade de passar para o cotidiano nos próximos anos. Pretendemos tocar também, se bem que de forma resumida, nos impactos acadêmicos, econômicos, culturais e sociais envolvidos nesta verdadeira revolução que está levando à "sociedade da informação".

Neste trabalho examinaremos a relação desses acontecimentos com o meio acadêmico, tanto como produtor quanto como usuário pioneiro da nova tecnologia. Existem muito poucas fontes de informação e principalmente de reflexão sobre o que está ocorrendo, pois o fenômeno é novo demais e parece ser muito profundo. Gostaríamos de aliviar esta situação com o presente documento, apresentando também uma série de referências úteis. Recomendamos, em particular, a leitura de quatro textos (4) para detalhes além do escopo deste trabalho. Uma descrição muito acessível dos aspectos técnicos das redes computacionais pode ser encontrada no livro de Comer (5). Reflexões notáveis sobre novas organizações econômicas e empresariais podem ser encontradas em dois trabalhos (6).

Uma versão mais curta deste artigo pode ser obtida pela leitura apenas das seções ímpares. As demais seções complementam o texto com uma abordagem mais detalhada e técnica.

Esperamos que este documento seja útil para que pessoas dos mais diversos níveis, entre elas as que têm poder de decisão sobre a forma e o volume de participação das suas organizações neste processo, sejam elas empresas, universidades ou órgãos públicos, possam avaliar melhor os acontecimentos e possam se orientar com maior segurança sobre como enfrentar o futuro e como melhor se preparar para ele. Uma coisa é certa: os autores, embora observadores deste cenário já por longos períodos (que variam de 10 a 35 anos), ficaram surpresos com o quanto aprenderam com a redação e montagem deste documento, motivo pelo qual agradecem à Academia Brasileira de Ciências pela oportunidade.

\section{OS ELEMENTOS DO PROCESSO: COMPUTADORES, DISCOS E CABOS}

Neste fim de século, a informação e o conhecimento se tornaram insumos básicos da economia global. Se essa frase soa como clichê, não é para menos: variações dela têm sido repetidas nos últimos anos pela imprensa especializada e leiga. Suas manifestações concretas vão desde o conhecimento necessário na indústria de alta tecnologia à previsão do tempo para a agricultura e a aviação, e passam pelo fluxo permanente de dados que alimenta o mercado financeiro.

Embora informação tenha sido sempre um elemento útil, a tecnologia recente permitiu pela primeira vez que se armazenasse e tratasse grande volume de dados, e que se comunicassem esses dados em grande velocidade em qualquer distância. O grande crescimento na escala da quantidade de dados se reflete numa mudança qualitativa da informação disponível; a facilidade de comunicação remove barreiras geográficas e permite que organizações funcionem de forma unificada.

Informação se apresenta de várias formas, e está em geral constituída de duas partes: uma forma de representação, ou seja, dados, e um mecanismo de interpretação, que transforma dados em informa-
O leitor tecnicamente inclinado pode avaliar esta velocidade através da comparacão das três edições sucessivas do livro Computer Networks de Tanenbaum, datadas de 1981, 1987 e 1996 (N), Prentice Hall, Englewood Cliffs; N Prentice Hall PTR, Uppe Saddle River; e NJ, Prentice Hall, UpperSaddle River, respectivamente). A primeir edição não fala de Internet e a segunda não fala nem de fibra óptica e nem de hubs para redes locais, só para mencionar alguns dos assuntos correntes da tecnologia neste momento

4 D. E. Comer, The Internet Book, NJ, Prentice Hall, Englewood Cliffs, 1995 Current Cites. http:// sunsite berkeley.edu/ CurrentCites. EDUCOM, Publications. http:// educomedu/web/pubs/ pubHomeFrame.html. N Scan by National Computer Board, Singapore. http:// www.ncb.gov.sg/nii/.

5 D. E. Comer, Computer Networks and Internets, $\mathrm{N}$, Prentice Hall, Upper Saddle River, 1996.

6 P. M. Senge, The Fifth Discipline: The Art and Practice of the Learning Organization, Doubleday, 1990; L. C. Thurow, The Future of Capitalism: How Today's Economic Forces Shape Tomorrow's World, William Morrow \& Company, 1996 
ção (e vice-versa). Por exemplo, o cérebro humano tem mecanismos para interpretar os desenhos de letras impressas como palavras e conceitos de uma língua, e extrair informação de um texto escrito. É de se notar que com o uso de mecanismos diferentes de interpretação, informações diferentes podem ser extraídas de um conjunto de dados, e por sua vez reapresentadas em outra forma, adequadas para outros interpretadores; isso configura uma transformação de dados, é uma das principais atividades envolvendo informação, e por si só pode gerar nova informação. Ela é executada por consultores e especialistas, que destrincham uma situação complicada para seu cliente, por tradutores, ao passar um texto de uma língua para outra, por computadores ao transformar uma grande massa de dados em relatórios inteligíveis ao ser humano.

\section{I. Armazenamento de informações}

O modo mais clássico de armazenamento de informação é através da palavra escrita, impressa. O acesso à informação estocada dessa forma é lento, difícil e de pouco rendimento. Para todas as etapas da manipulação da informação é necessária a presença do ser humano, e suas limitações na capacidade de aquisição de dados e processamento de grande volume constituem o principal gargalo do processo. Esse mecanismo é especialmente inconveniente para armazenamento de informação dinâmica, de atualização constante. Um exemplo pitoresco ocorre na prática legislativa brasileira: é comum encerrar-se diplomas legais com a expressão "revogamse as disposições em contrário". Entretanto, é praticamente impossível saber quais disposições foram revogadas e, para uma dada lei, é difícil saber se não foi suplantada por uma lei posterior. A dificuldade está em consultar e interpretar o grande número de textos legais.

Com o advento da computação surgiMais precisamente, $\mathrm{I} \mathrm{TB}=2$ $\mathrm{GB}=2^{20} \mathrm{MB}=2^{40}$ bites. Um bite equivale, aproximadamente, a um caracter de texto. zenar informação, com vistas a uma recu- peração expedita e posterior transformação. Os discos magnéticos são no momento o meio mais utilizado para combinar grande capacidade e alta velocidade de acesso. Já é viável para uma empresa média ter em um escritório uma capacidade de estocar o equivalente a uma biblioteca de porte razoável.

O crescimento da capacidade dos discos é um exemplo de processo exponencial, a ser delineado mais adiante. Assim, enquanto na década de 70 o megabite (MB) era uma unidade cara até para empresas e de uso raro, o início dos anos 80 colocou 5 MB na mesa do indivíduo, em discos que simultaneamente foram barateando e aumentando de capacidade. Atualmente, discos de 1 gigabite são acessórios baratos de microcomputadores, e já se comercializam competitivamente capacidades de terabites (aproximadamente 1 milhão de megabites) (7).

\section{2. Comunicação de dados}

A nova velocidade de comunicação de dados e informações é outro aspecto fundamental desse processo de crescente importância da informação. Termos como "aldeia global" deixaram de ser conceitos acadêmicos para virar lugar-comum do presente. Se tomarmos os meios de comunicação de massa, como rádio e $\mathrm{TV}$, por exemplo, temos novamente aqui uma situação análoga à da informação impressa: grande massa de informação direto do produtor ao receptor humano, que deve de alguma forma integrá-la como conhecimento. A informação é efêmera, e mesmo se guardada em fitas, de difícil recuperação e transformação. Uma mudança qualitativa fundamental está em se poder transmitir informação como dados reutilizáveis.

O progresso na comunicação de dados levou-a a atingir uma velocidade compatível com o volume de dados que se produz e consome atualmente. Novamente aqui é necessário que a informação transite automaticamente, uma vez que a presença do ser humano no meio do processo implica numa perda radical de eficiência.

Sobre a velocidade da comunicação é 
importante notar dois aspectos diferentes, a banda de passagem (volume de informação que pode ser passado simultaneamente), e a latência (tempo que cada bite de informação leva de fato para ir de um lugar ao outro). Quase sempre, ao se descrever um canal de comunicação, sua capacidade é descrita pela banda, o que pode dar uma idéia errada. Um exemplo interessante da diferença desses conceitos é resumido por Tanenbaum (8): com a pitoresca frase "Never under estimate the bandwidth of a station wagon full of tapes hurtling down the highway". De fato, com a gigantesca capacidade de armazenamento de pequenas fitas hoje em dia, é possível, por exemplo, transferir em uma viagem São PauloRio vários terabites, o que facilmente implementa uma banda da ordem de gigabites por segundo, impossível na presente tecnologia de telecomunicações. Entretanto, a latência envolvida é grande, envolvendo tempo de estrada, de tráfego urbano e de gravação e leitura das fitas.

Com o uso de telecomunicações, obtém-se baixíssima latência, desde que a banda disponível não esteja sobrecarregada. É por isso que se pode estabelecer comunicação que, para todos os efeitos, parece instantânea. O tráfego de dados se faz, na maior parte, por cabos de cobre e fibras ópticas, com algum uso de rádio e microondas. As fibras são de uso relativamente recente e, por permitirem velocidades muito altas, vêm se transformando no meio preferido.

O crescimento na capacidade dos canais de comunicação também é impressionante. Por exemplo, as linhas da espinha dorsal da rede que hoje é a Internet evoluíram de $56 \mathrm{Kbps}$ (1980) para $448 \mathrm{Kbps}$ (1984), 1.5 Mbps (1988), 45 Mbps (1990), com perspectiva de gigabites/s até o fim do século.

\section{3. Transformando dados em informação}

Essencial neste processo de mudança de escala na quantidade de informação que se pode tratar é a capacidade de processa- mento de dados em grande volume e com grande velocidade por computadores. Em todas as etapas, seja na produção, comunicação, armazenamento e tratamento de informações, encontram-se computadores capazes de lidar com grandes volumes de dados.

Nas décadas de 60 e 70 já se pôde notar a diferença resultante de meios magnéticos para armazenamento de dados e computadores para seu processamento. Isso teve um forte impacto no modo de trabalho de muitas empresas e órgãos governamentais. A partir da década de 80, essa capacidade de processamento chegou até as pequenas empresas e o usuário individual. No presente, as capacidades de processamento e armazenamento de um computador doméstico são comparáveis às de supercomputadores de quinze anos atrás, e inimagináveis no início da década de 70.

Com o acoplamento direto de máquinas de processamento aos meios de comunicação resolveu-se, em grande parte, o problema da latência na transmissão de dados do produtor ao consumidor. As redes de computadores permitem que dados trafeguem em grande volume e velocidade e sejam transformados em informação dentro de uma escala de tempo sem comparação na história.

É interessante que, a partir do momento em que essa conjugação de meios se tornou possível, já ficou claro onde estava o futuro:

"The information revolution produced a knowledge explosion. Advances in the development and use of computerized information-processing networks, some of them on a world wide basis, suggest not only further 'explosion' of knowledge but revolutionary steps in generation and reorganization, storage and distribution. [...] Anything that can be done anywhere in the world with any computing system could now be done at any standard teletypewriter or other operator's console -provided that the communications connections have been made and the computer files and programs modified to permit general access from remote points"(9).
8 A. S. Tanenbaum, Computer Networks, op. cit., 1996, p. 83.

Merril M. Flood [5, Information Processing, 9, pp. 567-74] 1977. 
O que estava para vir e concretizar essas previsões, muito além do que se poderia esperar em 1977, era a total capilarização desses meios, através de dois elementos:

- o microcomputador, que trouxe o poder de processamento às mãos do indivíduo;

- a Internet, que permitiu que todos os computadores a ela conectados se interligassem para troca de dados.

\section{CARACTERÍSTICAS MARCANTES}

Tendo isolado os principais elementos do processo na seção anterior, examinamos aqui as características que mais contribuem para a manutenção do seu crescimento exponencial por longos períodos de tempo. Maiores considerações sobre o próprio processo exponencial de crescimento também serão feitas. Ao mesmo tempo, esperamos que esta enumeração de alguns dos aspectos mais marcantes do sistema, intercalados com exemplos, dêem, principalmente para o leitor leigo nessas técnicas, uma dimensão das enormes dificuldades que tiveram que ser transpostas para que a tecnologia chegasse ao seu estágio de desenvolvimento atual.

\section{I. Interatividade}

10 V. Bush, "As We May Think", in Atlantic Monthly, 176 (I) pp. |01-8, July, |945. Reimpresso em CD-Rom: The New Papyrus, Microsoft Press, 1986. Veja também em http:/ ccat.sas.upenn.edu/jod/texts/ vannevar.bush.html.

II D. C. Engelbart and W. K. English, "A Research Center for Augmenting Human Intellect", in A. Press (ed.) Proc. of the 1968 Fall Joint Computer Conference,pp. 395 410, 1968; J. B. Smith and S. F. Weiss, "An Overview of Hypertext",

Communications of the ACM 31, pp. 816-9, 1988.

12 T. H. Nelson, "Getting It Out of Our System", in G. Schechter (ed.), Information Retrieval: A Critical Review, Thompson Books, Washing ton, DC, 1967, pp. |91-210. participantes. Basicamente, pode-se ter a interatividade de uma ligação telefônica com a capacidade de transmitir informação de um canal de televisão. Por outro lado, também é possível ter a capacidade de transmissão e registro permanente de mensagens como no telex ou no fax, combinada com a possibilidade de envio de grandes quantidades de informação em formatos arbitrários.

\section{2. Hipertexto}

O hipertexto é um dos paradigmas básicos em que a teia mundial se baseia. Ele é uma espécie de texto multidimensional em que, numa página, trechos de texto se intercalam com referências a outras páginas. Clicando com o mouse numa referência dessas a página corrente é substituída pela página referenciada. É muito fácil formar uma idéia grosseira do que é um hipertexto: basta pensar nas edições mais modernas da Enciclopédia Britânica que se constituem de uma mistura de informações com apontadores para outros trechos da própria enciclopédia.

A invenção do conceito costuma ser atribuída a Vannevar Bush que descreve o memex num artigo clássico, escrito em 1945 , antes mesmo do aparecimento dos primeiros computadores (10). A seguir Doug Engelbart fez, em 1968, uma demonstração histórica numa conferência de computação realizando o memex com a utilização de um mouse (11). O termo "hipertexto" foi lançado por Ted Nelson, nos anos 60 (12).

O hipertexto é muito apropriado para a representação de informações no computador por dois motivos: permite subdividir um texto em trechos coerentes e relativamente curtos, facilitando a sua organização e compreensão, e permite também fácil referência a outras partes do texto ou a outros textos, totalmente independentes, muitas vezes armazenados em locais distantes. Isso cria uma característica própria de leitura da informação que, após um curto processo de adaptação, passa a ser intuitivo para o usuário, que se refere a essa leitura como "navegação". 


\section{3. Multimídia}

A informação pode ser comunicada por múltiplos meios: textos, imagens, sons, filmes, animações, cheiros, sabores, diversas características detectadas pelo tato, etc. Alguns desses meios podem ser digitalizados, outros, como cheiro, sabor e tato, ainda não chegaram nessa fase. $O$ termo multimídia costuma se referir à conjunção das múltiplas formas acima, que já podem ser digitalizadas e que são correntemente usadas em computadores, em geral num ambiente de hipertexto. É importante notar que a forte expansão das capacidades de processamento e de armazenamento dos computadores foi imprescindível para a viabilização do uso de vários dos meios acima mencionados. Por exemplo, o armazenamento e processamento de vídeos ou animações seria totalmente impensável quinze anos atrás, e ainda hoje apresenta sérias dificuldades técnicas.

\section{4. Digitalização}

Observa-se hoje um avanço muito forte da digitalização da informação, uma condição necessária para o amplo uso dos computadores no seu processamento. É importante notar que a digitalização da informação foi um dos marcos da invenção dos computadores, já que na época a idéia predominante era a da computação analógica, mais adequada às técnicas matemáticas dominantes na época. O livro Computer and the Brain, última obra de John von Neumann (13), dedica amplo espaço à discussão das vantagens e desvantagens de cada modo de computação: digital ou analógica. Verificamos hoje que a solução digital domina completamente o cenário, haja vista que já passamos da época da digitalização do sinal sonoro e que estamos no limiar da digitalização do sinal de televisão e da tecnologia telefônica, ao mesmo tempo em que fica cada vez mais raro o uso de sinais analógicos para efeito de processamento da informação.

\section{5. Computação distribuída}

O aparecimento de redes de computadores permitiu a utilização de um novo paradigma computacional que se mostrou, com o passar do tempo, extremamente poderoso. Estamos nos referindo à possibilidade de distribuição do processamento entre computadores diferentes. Mais do que a simples subdivisão de tarefas, esse paradigma permite a repartição e a especialização das tarefas computacionais conforme a natureza da função de cada computador. Um exemplo típico é a chamada arquitetura cliente/servidor, na qual muitos computadores "clientes" se comunicam com computadores "servidores" que nada mais são do que processos especializados na execução de certas tarefas, como cuidar de ar-
13! von Neumann, The Computer and the Brain, New Haven, Yale University Press, 1958

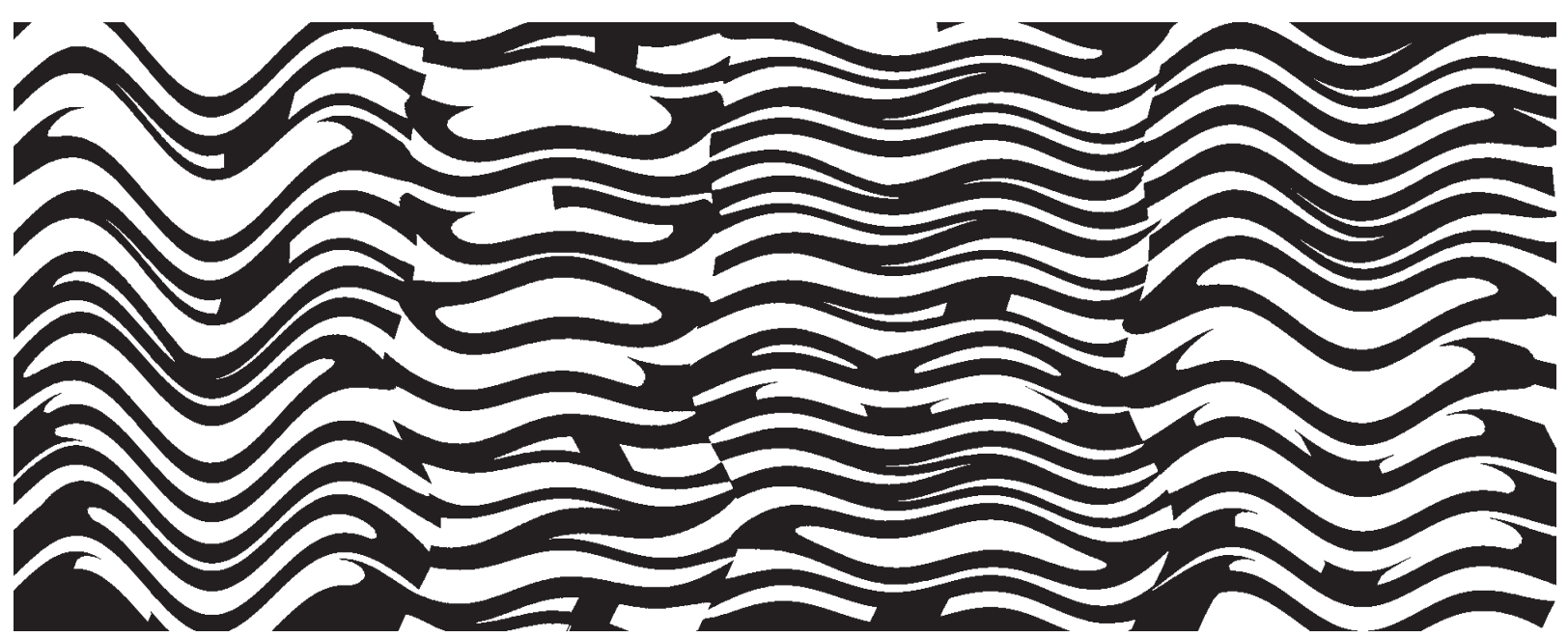


quivos ou administrar bancos de dados.

Numa tentativa de ilustrar este conceito, mencionamos que a mistura do paradigma cliente/servidor com a idéia de hipertexto levou ao estágio atual da teia mundial que se apóia sinergeticamente nos dois paradigmas. Para melhor apreciar esse ponto, sugerimos ao leitor a consulta do número especial da Communications of the ACM (Association for Computing Machinery), dedicado ao tema de hipertexto, escrito em 1988 (14), na véspera da introdução da teia mundial. Hipertexto já era amplamente usado na época, mas nada naquele número permite antever a explosão da teia. Talvez o ingrediente mais importante da teia, que está faltando naquele documento, seja a introdução do paradigma cliente/servidor num ambiente de hipertexto. Ocliente (browser) especializase em obter e apresentar páginas, enquanto o servidor especializa-se em montar e disponibilizar as páginas na rede.

\section{6. Compartilhamento de canal}

Um aspecto que está tendo tremendo impacto no uso das redes é o enorme grau de compartilhamento entre milhares ou milhões de usuários de canais digitais de comunicação através da técnica chamada de comutação de pacotes (packet switching). A idéia básica é quebrar longas mensagens em pedaços pequenos que são tratados independentemente e de maneira assíncrona. Isso permite a imediata liberação de um canal de comunicação por um usuário que não o esteja usando, muito embora o canal esteja à sua inteira disposição em caso de necessidade. Assim, os diversos usuários utilizam o mesmo canal de comunicação permitindo que os períodos

14 J. B. Smith and S. F. Weiss, "An Overview of Hypertext", in op. cit., pp. 816-9.

15 Foi fundamental para a existência do Linux a experiência prévia em cooperação do projeto GNU da Free Software Foundation, cujo software constitui parte fundamental do sistema operacional Linux. sadas pelo congestionamento são igualmente distribuídas entre os usuários. Essa situação facilita a adaptação de toda a comunidade às situações de sobrecarga de tráfego nas linhas, uma vez que a demora na obtenção dos serviços requisitados causa automaticamente a diminuição da demanda de comunicação.

\section{7. Cooperação}

A rede, com os seus mecanismos de comunicação já bem desenvolvidos, revelou-se um catalisador e mesmo um instrumento insuperável para a cooperação entre pessoas e grupos trabalhando em um objetivo comum, bem definido, a ponto de surpreender até mesmo os maiores especialistas da área. Existem milhares de exemplos desse fenômeno, mas talvez o caso mais dramático seja aquele do desenvolvimento cooperativo do sistema operacional Linux.

O Linux é um entre os inúmeros sistemas operacionais da família Unix. Ele está sendo desenvolvido desde 1991 através da Internet por milhares de ativistas, geralmente entre 20 e 30 anos de idade, que, via de regra, não se conhecem pessoalmente (15). Acreditamos que qualquer especialista que fosse chamado a opinar em 1990 sobre a possibilidade de sucesso de uma operação de tamanha complexidade, desenvolvida por uma equipe tão numerosa e tão heterogênea, sem laços de comunicação face a face, concluiria pela mais absoluta impossibilidade de sucesso da tarefa. Pois bem, o Linux roda de forma estável desde 1993. Além disso, ele é totalmente gratuito e distribuído como software livre, isto é, junto com o seu programa fonte, que pode ser alterado conforme os interesses ou necessidades de cada usuário.

Desenvolvido inicialmente para a plataforma PC, literalmente disponível em qualquer esquina, o Linux hoje conta também com implementações para as arquiteturas da família 68000 da Motorola, Alpha da Digital e Sparc da SUN. Ele está começando a ser usado também em arquiteturas muito complexas na área da supercomputação. Implementações para os 
microprocessadores PowerPC e MIPS estão em andamento e bem adiantadas. Várias dessas implementações têm o apoio explícito das empresas envolvidas nas respectivas arquiteturas (Digital, NEC e IBM), em que pese o fato de estas empresas possuírem o seu próprio sabor de Unix em que investiram já milhões de dólares.

Por outro lado o Unix é, sem dúvida, um sistema operacional de uso amplo, muito desenvolvido e versátil, tanto que é o único que está implementado na quase totalidade dos tipos de computadores. Entretanto, ele foi bastante prejudicado pela falta de uma normatização ampla, o que levou a uma dispersão das características do sistema, pois cada fabricante tentou seguir as suas próprias idiossincrasias.

Por esses fatos todos, consideramos hoje em dia o Linux como o único sistema com possibilidades concretas de alcançar o status de padrão de fato da família Unix. Note-se que, se não houvesse microcomputadores ou rede Internet, certamente não haveria Linux!

\section{8. Informação distribuída}

Como no caso da computação distribuída, a rede abriu a possibilidade de armazenamento distribuído da informação. Isto é, existe agora a possibilidade de se guardarem informações similares e de mesma natureza em locais distintos. Um servidor especializado disponibilizará os dados para quem deles precise, numa arquitetura cliente/servidor. É necessário dizer que a realização desse paradigma ainda está muito aquém das suas possibilidades e que grandes avanços podem ser esperados nesse campo. Os exemplos que existem são simples mas impressionantes pelo potencial que oferecem. Vamos dar apenas dois exemplos.

Nosso primeiro exemplo é a própria teia mundial, pois o conjunto total de páginas pode ser visto como um único banco de dados de informações, uma espécie de enciclopédia totalmente descentralizada, sem nenhum tipo de coordenação além da sintaxe comum para a apresentação da infor- mação. Uma situação dessas dá a impressão, à primeira vista, de uma anarquia total, na qual a localização de uma agulha específica num palheiro tão descoordenado seria absolutamente impossível. Difícil se enganar mais! Não levou mais do que um ou dois anos para que surgissem novas ferramentas, adaptadas ao ambiente da rede, que resolvessem essas questões de forma brilhante, tornando a localização da informação um simples exercício. Temos em mente os indexadores, como o sistema de índices Alta Vista (16) descrito na subseção 4.6 deste documento.

Apesar do sucesso dos indexadores, existem ainda inúmeros problemas a serem resolvidos no sentido de aprimorar e agilizar a localização das informações na teia. Os indexadores existentes baseiam-se em critérios sintáticos e freqüentemente oferecem um universo muito numeroso de soluções, sem poder ordená-las segundo sua relevância para o pesquisador. Isso pode dificultar a localização ágil da informação procurada (17).

O segundo exemplo é um banco de dados de informações muito simples, quase sem estrutura, e cujo controle seria absolutamente impossível centralizar. Trata-se do conjunto de nomes de recursos computacionais espalhados pela Internet. Isso é usado em todas as comunicações da rede, em particular no endereçamento de mensagens de $e$-mail. De fato, o conjunto de nomes e endereços na rede local do Instituto de Matemática e Estatística da USP nada tem a ver, e nada deve ter a ver, com o conjunto de nomes e endereços na rede local da Reitoria da Universidade de Paris. E esse banco de dados distribuídos, chamado de Domain Name System, está montado de tal forma que esses dados, embora administrados e constantemente atualizados de forma totalmente descoordenada, podem ser igualmente usados pela totalidade de agentes computacionais ligados à Internet.

Ainda assim, é importante observar que a montagem de um banco de dados distribuídos que reflita a estrutura de uma grande organização ainda é de uma dificuldade proibitiva.

\footnotetext{
6 R. Seltzer, E. I. Ray, and D. S. Ray, The AltaVista Search Revolution, Berkeley, Osborne McGraw-Hill, 1997.

17 C. M. Bowman, P. B. Danzig U. Manber, and M. F. Schwartz "Scalable Internet Resource Discovery: Research Problems and Approaches", in Communications of the ACM 37 (8), 1994, pp. 98-107, I14 O. Etzioni, "The World-Wide Web: Quagmire or Gold Mine?" in Communications of the ACM, 39 (II), 1996, pp $65-8$.
} 


\section{9. Normatização e sistemas abertos}

A área da informática é caracterizada historicamente pelo surgimento de padrões de fato para onde converge a maioria, se não a totalidade, dos usuários dentro de um segmento homogêneo. As técnicas concorrentes com o padrão de fato, por melhores que possam eventualmente ser, estão condenadas à morte, às vezes instantânea, às vezes lenta e sofrida. Existem inúmeros exemplos, tanto em hardware quanto em software, desse processo.

Os padrões de fato podem ser públicos ou proprietários. Nos casos de padrões proprietários tornarem-se o padrão de fato, como é o caso da família Windows de sistemas operacionais da Microsoft, é garantia de vendas praticamente sem concorrência. Existem também casos de empresas que desenvolvem um conjunto de normas referentes a uma dada tecnologia e tornam essas normas públicas. A publicação das normas diminui muito a vantagem comercial da empresa mas aumenta muito a predisposição do público pela sua adoção. As empresas SUN e Netscape utilizam bastante esse expediente (NFS, Java, SSL, etc.).

No caso da Internet, as suas normas e protocolos são públicos se fixados após amplas consultas a toda a comunidade. Trata-se de uma sequiência de documentos chamados Request for Comments (RFC) que podem ser encontrados na teia (18). A primeira RFC é datada de 4 de julho de 1969 e, em 2 de fevereiro de 1997, a mais recente tem o número 2092. Existe um

18 Index of Requests For nic.merit.edu/documents/.

190 standard número I da Internet. std0 I-rfc/920. txt (Untitled). ftp://nic.merit.edu/ documents/std/stdol rfc 1920. txt.

20 A. S. Tanenbaum. Computer Networks, op. cit., 1996, p. 40

21 Uma função exponencial é uma função da forma $f(t)=$ $\exp (a t+b)$ onde $a \quad 0$ e $b$ são constantes e exp $(x)$ representa e elevado a $x$. Todas as funções exponenciais são monotônicas, podendo ser crescentes (se $a>0$ ) ou decrescentes (se $a<0$ ). complexo mecanismo que normatiza a própria edição da seqüência RFC e que determina também o processo de padronização (19), isto é, como e quando uma RFC vira um padrão (STD). Existem hoje aproximadamente 50 padrões nas séries STD. Os padrões são periodicamente revistos e atualizados, tudo dentro da séries RFC. Dessa forma os padrões são amplamente divulgados após a sua filtragem por uma comunidade numerosa. Tudo isso facilita sobremaneira a adoção universal dessas normas.
É preciso observar que qualquer processo de padronização é muito complexo e existem muitos riscos de o padrão não ser finalmente adotado. Se o padrão for fixado muito cedo, corre-se o risco de ficar obsoleto prematuramente, penalizando os que o adotaram. Se o padrão for fixado muito tarde, corre-se o risco de não ser seguido por já existirem outros mecanismos satisfatórios em funcionamento cuja desativação seria inconveniente. Por esses motivos, além de interesses comerciais evidentes, há muitos padrões que viram letra-morta, às vezes antes mesmo de serem publicados. Um exemplo é o modelo ISO-OSI para redes de computadores que, embora muito bonito conceitualmente, em pouco tempo virou uma peça apenas literária diante da força da adoção maciça da Internet, que não o seguiu por ser anterior a ele (20).

Felizmente, o mecanismo RFC encontrado pela Internet possibilitou um mecanismo ágil e eficiente de padronização que, até agora, permitiu as readaptações que a rede exige devido aos freqüentes avanços tecnológicos e também ao volume crescente de adesões. Isso foi e está sendo essencial para o bom funcionamento da rede pelo mundo afora, principalmente quando atentamos para a extraordinária rapidez com que a rede se desenvolve.

\subsection{Crescimento exponencial}

As funções exponenciais são caracterizadas pelo fato de que ao longo do tempo seus valores dobram, no caso de exponenciais crescentes, ou diminuem para a metade, no caso de exponenciais decrescentes, num intervalo de tempo constante independente do valor da função num determinado instante (21).

Funções exponenciais decrescentes ocorrem freqüentemente na natureza. Talvez o exemplo mais conhecido seja a variação da intensidade de radioatividade de um material radioativo. Esses materiais são caracterizados pela sua meia-vida, o que nada mais é do que o intervalo de tempo em 


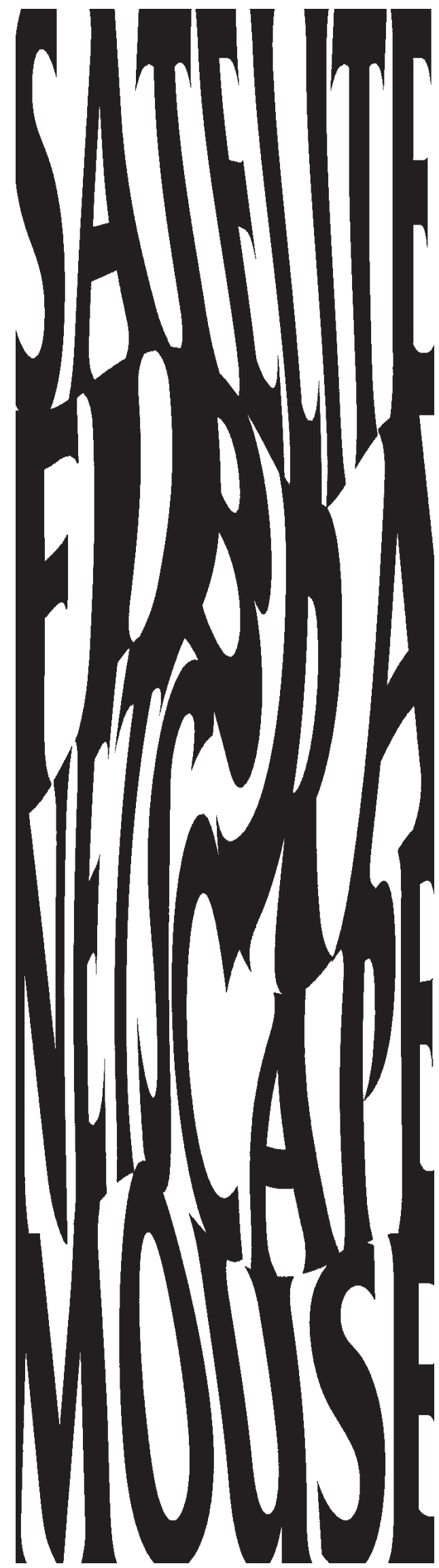

que diminui para a metade a intensidade radioativa daquele material.

Funções exponenciais crescentes são muito raras na natureza e quando ocorrem duram um tempo limitado, em geral curto, pois na natureza os recursos disponíveis são sempre limitados. Como as funções exponenciais crescentes têm um crescimento muito acentuado, o valor da função rapidamente excede o limite imposto pelos recursos disponíveis.

As áreas da computação e da comunicação parecem desafiar essa afirmativa. De fato, elas vêm se caracterizando, já há década, por uma sucessão de fenômenos exponenciais crescentes com constantes de tempo de duplicação que variam entre alguns meses até poucos anos. Talvez o processo exponencial mais longo de que se tem notícia na natureza se refira ao crescimento do poder computacional disponível por US\$ 1 . Esse parâmetro vem seguindo uma exponencial crescente de constante de tempo de aproximadamente 18 meses que vem sendo observada desde o lançamento dos primeiros computadores comerciais em meados da década de 1950. Ou seja, desde essa época, decorridos 40 anos, houve uma duplicação do poder computacional disponível por um dólar 27 vezes seguidas, ou seja, uma variação de 134 milhões de vezes em 40 anos. Estes números são aproximados pois não conhecemos um estudo preciso nessa direção nos termos descritos. Tal estudo, por sinal, pode ser bastante complicado pois não está claro como medir o poder computacional de um sistema computacional complexo que tem muitos componentes, cada um dos quais sujeito a sua própria lei exponencial de desenvolvimento. De qualquer forma, os números apresentados oferecem uma indicação geralmente aceita como precisa.

Uma outra lei similar é conhecida como lei de Moore. Trata-se de Gordon Moore, um dos fundadores da Intel, maior fabricante mundial de circuitos integrados. Ele enunciou a sua lei em 1965, numa época 
em que um microchip podia integrar algo como quatro transistores: "o desempenho de microchips produzidos em massa vai dobrar a cada 18 meses" (22). Nota-se que o limitante de preço nesse caso é substituído pela condição de produção em massa, o que dá um efeito similar, já que só é possível produzir em massa componentes suficientemente baratos para poderem ser absorvidos pelo mercado. Por outro lado, a própria produção em massa acaba barateando esses componentes. Todos esses fenômenos são observados na área da computação. A Figura 1 dá suporte à lei de Moore.
Outra quantidade que vem seguindo uma lei exponencial crescente é a largura de banda disponível para consumo amplo em linhas de transmissão digital. Este processo exponencial começou mais tarde do que o processo do aumento do poder computacional, mesmo porque durante os 15 primeiros anos de existência comercial dos computadores não havia, do ponto de vista de transmissão de dados, nenhum interesse nessas linhas. O processo, porém, vem se acelerando muito nos últimos anos, principalmente com o advento da fibra óptica. Há previsões de que o crescimento desse processo ultrapassará, e muito, o crescimento do poder computacional (23).

\section{Figura 1}

Crescimento da CAPACIDAde de MEMória disponível POR US\$:
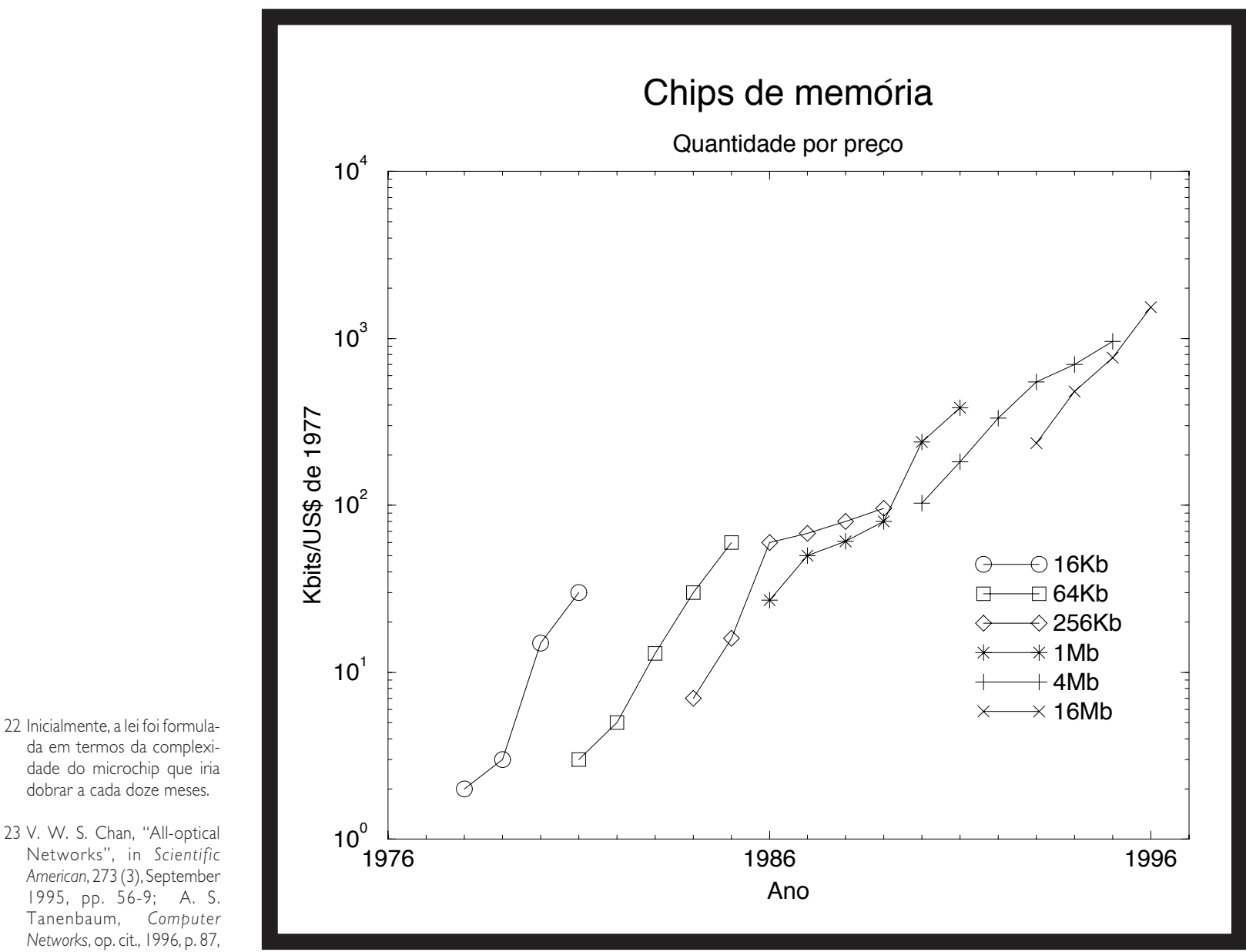
Figura 2

Crescimento da rede InTERnet:

ELA DOBRA A CADA 15 MESES

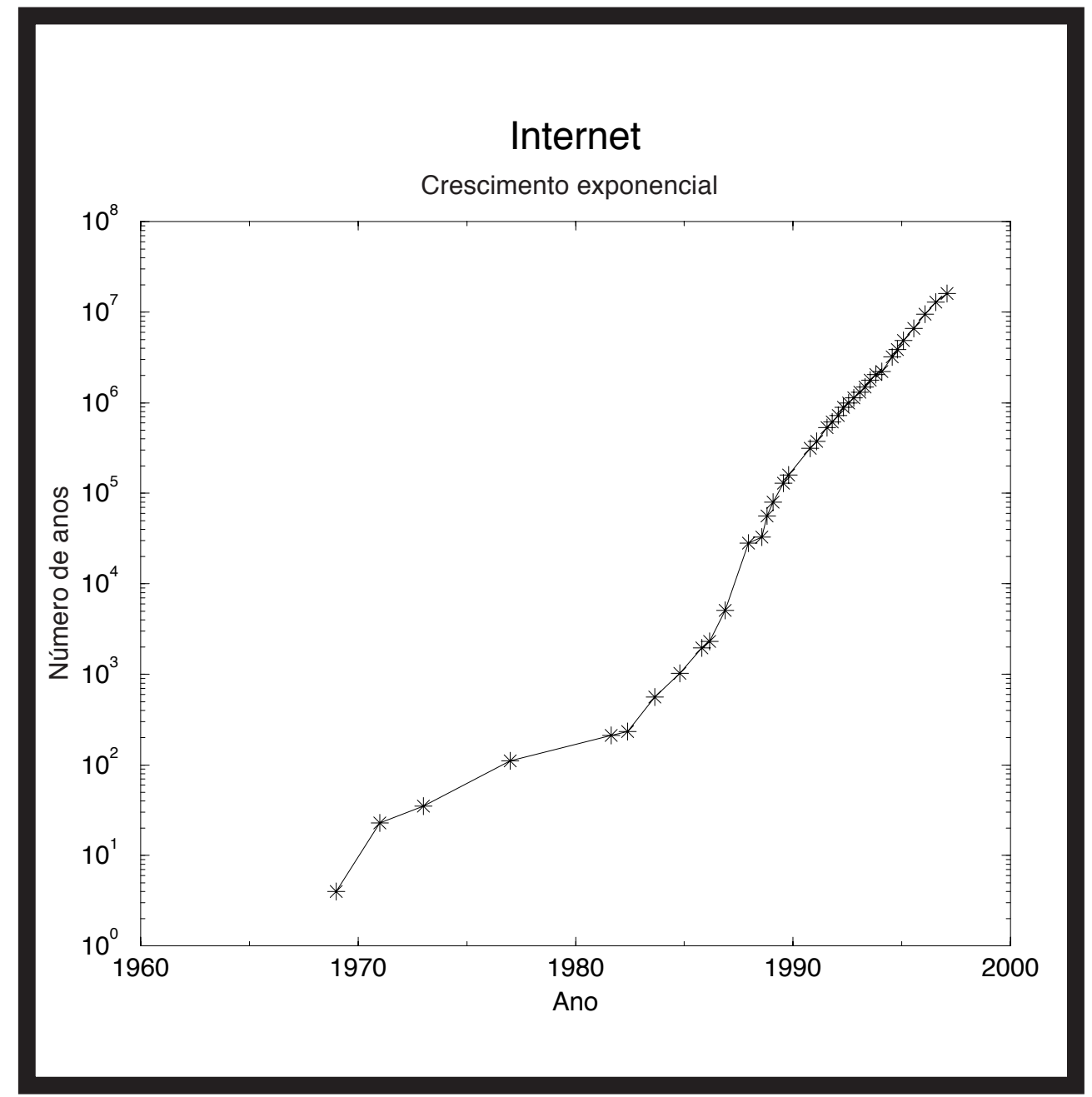

Observamos que não se espera uma interrupção desses fenômenos nos próximos 15 a 20 anos, ou melhor, não se conhecem, neste momento, barreiras científicas ou tecnológicas que impossibilitem a continuação do processo de evolução tecnológica exponencial da área de informática ou de telecomunicações nesse período (24). Dessa forma, não está descartada a possibilidade de uma nova melhora da ordem de 1.000 vezes, nos próximos 15 a 20 anos, na capacidade de processamento de computadores. O progresso poderá ser mais dramático ainda nas capacidades de transmissão dos canais de comunicação. De fato, não estão descartadas velocidades de 25 Tbps (25 trilhões de bites por segundo) num futuro não muito distante. Esses ganhos, se concretizados, mais uma vez mudarão completamente o perfil global da área em direções que são absolutamente imprevisíveis neste momento. Como será o mundo em que cada mesa terá um computador que hoje valeria US\$ 2.000.000,00, comunicando-se com velocidades um milhão de vezes maiores do que as atuais? Que software rodará em tal ambiente?
24 V. W. S. Chan, "All-optical Networks", op. cit.; D. A. Patterson, "Microprocessors in 2020", in Scientific American, 273 (3), September 1995, pp. 48-51. 


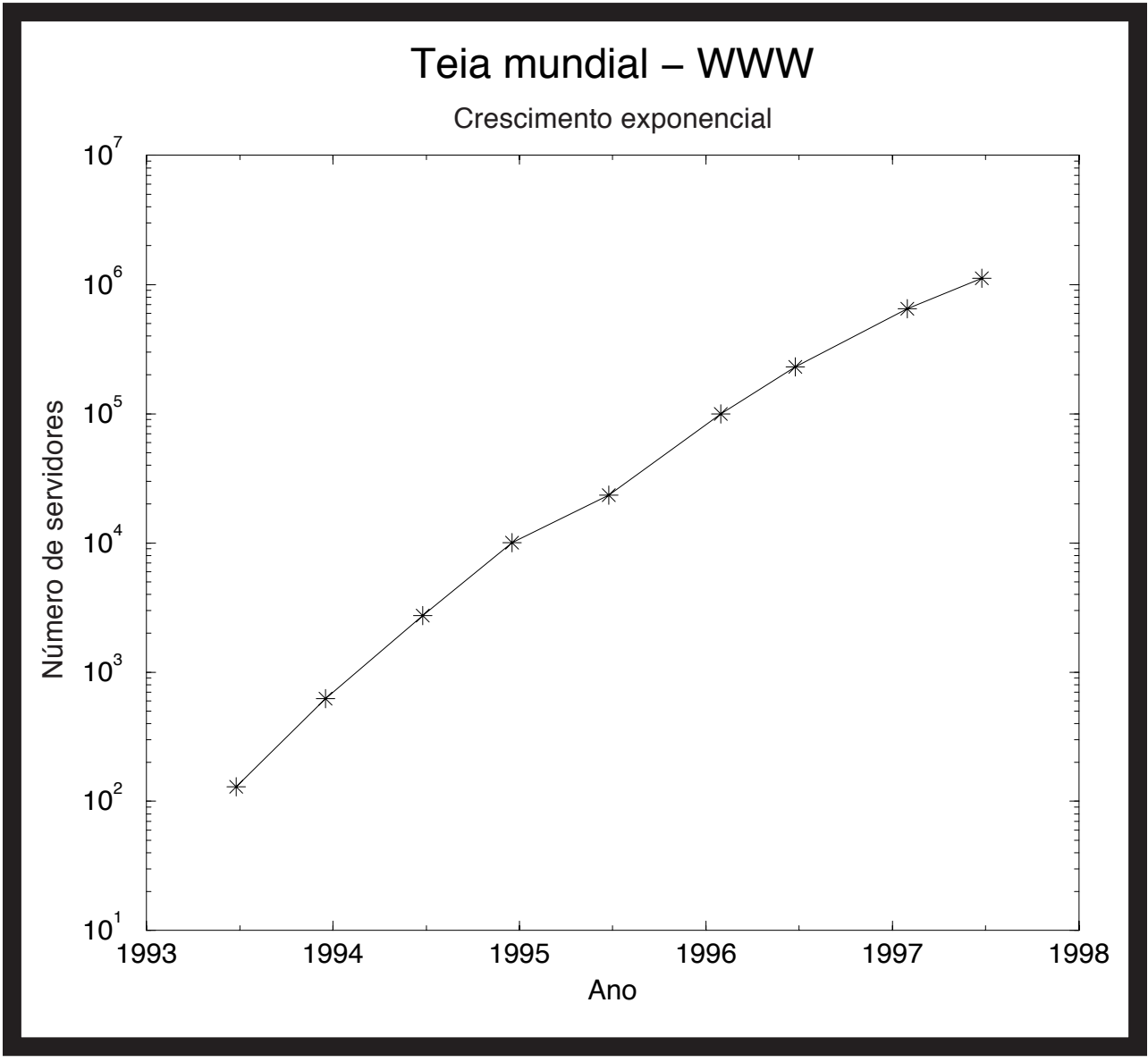

25 J. L. Hennessy and D. A Patterson, Computer Architecture: A Quantitative Approach, Morgan Kaufmann Pub., 2nd edition, 1996.

26 Network Wizards, Interne Domain Survey. http:// www.nw.com/zone/WWW top.html. A. M. Rutkowski, Internet Trends. http:// www.genmagic.com nternet/Trends/. R. Zakon. Hobbes' Internet Timeline. http://www.isoc.org/zakon/ Internet/History/HIT. html.

27 M. Gray, Internet statistics: Web growth, internet growth. http://www.mit.edu/ people/mkgray/net/. R Zakon, Hobbes' Internet Timeline. http:// www.isoc.org/zakon Internet/History/HIT. html.
A título de exemplificar o processo exponencial de crescimento incluímos três gráficos. No primeiro, mostramos a evolução dos preços de seis pastilhas de memória. Os preços são ajustados para o valor do dólar americano em 1977 e os dados foram extraídos do livro de Hennessy e Patterson (25). No segundo, mostramos a evolução do número de computadores ligados na Internet, com dados extraídos de várias fontes (26). Dos dados da Figura 2 concluímos que desde a sua fundação, 27 anos atrás, o número de computadores na Arpanet/Internet dobra a cada 15 meses, aproximadamente. Mantido esse ritmo de crescimento, a Internet terá tantos computadores quantos serão os habitantes do planeta Terra no ano de 2011. Será que chegaremos lá? Em mais 15 anos apenas? O ter- ceiro gráfico, cujos dados são provenientes de duas fontes (27), mostra a espantosa evolução do número de servidores da teia mundial. Este é o mais recente fenômeno da Internet e constitui o processo exponencial mais rápido de que se tem notícia no presente contexto. A Figura 3 ilustra o processo, mostrando que o número de servidores da teia dobra a cada 14 semanas, desde o seu advento em 1993. Esse crescimento extremamente rápido é provocado pela adoção quase instantânea da nova tecnologia pela Internet já existente. É provável que passado o período de adoção inicial o crescimento da teia passe a acompanhar o crescimento da Internet.

Como se vê, o crescimento exponencial está na base de qualquer entendimento do passado e do futuro da área da informática. 
Mas é muito difícil raciocinar com processos exponenciais crescentes. A primeira constatação que conhecemos do crescimento exponencial da capacidade computacional foi feita por John von Neumann (28). Acreditamos, porém, que em 1957, época da sua morte, nem mesmo Von Neumann tivesse a visão do que viria em seguida. Uma consideração muito mais precisa do crescimento exponencial, incluindo previsões para um futuro distante, encontra-se no livro de Licklider (29) sobre a "biblioteca do futuro", escrito em 1964. Uma das previsões mais impressionantes sobre o desenvolvimento da informática encontra-se nesse livro e está citado na íntegra na subseção 6.11 deste trabalho.

\section{ASPECTOS HISTÓRICOS}

Do ponto de vista físico, redes de computadores se compõem de computadores e de ligações entre eles. A rede pode necessitar de outros elementos ativos, além dos computadores propriamente ditos, que são computadores especializados no tratamento dos dados que trafegam pela rede. Um componente essencial para qualquer rede é o conjunto de software que realiza tanto os serviços disponíveis na rede, visíveis para o usuário, quanto os serviços de comunicação entre os computadores, em geral invisíveis para o usuário final. Assim, é apropriado começar a história das redes com algumas palavras sobre a história dos computadores. O leitor interessado encontrará muito mais informações na literatura especializada (30).

\section{I. Computadores}

O primeiro computador digital, o Eniac, foi inaugurado em fevereiro de 1946, cinqüenta anos atrás, construído na Universidade da Pensilvânia durante a Segunda Guerra Mundial, dentro de um programa do exército americano que procurava automatizar o cálculo de tabelas balísticas Imediatamente se reconheceu a utilidade universal do invento e passou-se à constru- ção de modelos com mais memória interna que incorporavam o conceito de programa armazenado, fundamental para a utilização prática da máquina. Até os primeiros anos da década de 1950 várias máquinas foram construídas. Elas eram todas diferentes e todas artesanais, mas todas seguiam a chamada arquitetura Von Neumann, delineada nos primeiros trabalhos sobre a construção de computadores digitais (31). Nos meados da década de 1950 começou a produção dos primeiros computadores comercialmente disponíveis. A IBM saiu na frente nesse processo, o que lhe valeu o domínio quase absoluto do mercado de informática até meados da década de 1980 e um papel predominante até hoje.

Até 1960 todos os computadores eram baseados em válvulas nos dez anos seguintes temos o predomínio de computadores transistorizados. A partir de 1970 aumenta o uso de circuitos integrados e por volta de 1978 inicia-se a era dos computadores baseados em microprocessadores que dominam o mercado até hoje, após um desenvolvimento espetacular dessa tecnologia nos últimos trinta anos. É interessante destacar aqui o papel fundamental da pesquisa em Física da Matéria Condensada, uma aplicação da Mecânica Quântica, no desenvolvimento dos semicondutores utilizados nos circuitos integrados, baseados em silício, um material barato e abundante na natureza.

Com a miniaturização do hardware veio o barateamento dos computadores e a conseqüente disseminação dos mesmos. Inquestionavelmente um marco nesse processo foi a introdução do computador pessoal, que se consolidou definitivamente num curto espaço de cinco ou seis anos a partir do seu lançamento, em 1977, pela Apple. Outro marco foi a introdução das estações de trabalho por volta de 1983, sendo que a tendência atual é a fusão entre a estação de trabalho e o computador pessoal, tal é o aumento de capacidade do último e a diminuição dos preços da primeira. Estima-se que existem hoje entre cem milhões e duzentos milhões de computadores em operação.
28 J. von Neumann, "Defense in Atomic War", in Journ. Am. Ordnance Assoc. Washington DC, 1995, pp. 21-3.

29 J. Licklider, Libraries of the Future, Cambridge, The MIT Press, MA, 1965

30 A. Goldberg (ed.), A Histon of Personal Workstations. Addison-Wesley, Reading, MA, 1988; H. H. Goldstine The Computer from Pascal to von Neumann, Princeton University Press, 1972: T. Kowaltowski, "Von Neumann: suas Contribuições à Computação", in Estudos Avançados, 10 (26) 1996, pp. 237-60; N Metropolis, !. Howlett, and G.-C. Rota (eds.), A Histor of Computing in the Twentieth Century, New York, Academic Press, 1980: L. Press, "Before the Altair-th History of Personal Computing", in Communications of the ACM, 36 (9) 1993, pp. 27-33; B. Randell (ed.), The Origins of Digital Computers, Third Edition, Springer-Verlag, 1982

3| T. Kowaltowski, "Von Neumann: suas Contribuições à Computação", op. cit 
Até 1980 a computação era basicamente centralizada dentro de cada organização com a ocorrência, a partir dos anos 70, de grandes sistemas de terminais "burros" (isto é, sem capacidade de processamento local) ligados num grande e "poderoso" computador central. Isso aliviava o desconforto da concentração dos equipamentos e permitia um acesso mais espalhado a eles. A solução deixava a desejar, porém, devido a dificuldades de gerenciamento e de esca labilidade do sistema e à falta de possibilidades de personalização do ambiente computacional de cada usuário.

Durante a primeira metade dos anos 80 começa uma tendência de proliferação de computadores pessoais isolados e de estações de trabalho interconectadas em redes locais para responder à demanda computacional. Com a possibilidade de alocar o computador perto do usuário e cada vez mais em seu próprio ambiente de trabalho, aumenta a demanda por poder computacional e cada vez mais tarefas passam a ser feitas com a intervenção do computador. Nessa época o computador pessoal autônomo começa a apresentar limitações devido ao seu isolamento e à dificuldade de gerenciamento de grande número de equipamentos muito parecidos que exigiam atenção individual. Isso leva à popularização de redes locais de microcomputadores por volta de 1990 .

Emambientes desenvolvidos, hojeem dia, o computador pessoal é integrado numa rede local com vários servidores dos mais diferentes serviços (em geral os servidores são estações de trabalho ou computadores de alto desempenho). Essa rede local está conectada à rede mundial Internet, fazendo com que quaisquer dois computadores na Internet possam trocar informações em grandes quantidades e com grande eficiência. Nessa realidade não é raro que uma pessoa use o seu terminal durante várias horas por dia para as finalidades mais diversas possíveis.

\subsection{A Arpanet}

A idéia da construção de uma rede de computadores que pudesse trocar informações surgiu na Advanced Research Projects
Agency (Arpa) do Departamento de Defesa dos EUA quando, em 1962, a Agência contratou J. C. R. Licklider (32) para liderar as suas novas iniciativas através do Information Processing Techniques Office (IPTO) da Agência. Um dos sonhos de Licklider era uma rede de computadores que permitisse o trabalho cooperativo em grupos, mesmo que fossem integrados por pessoas geograficamente distantes, além de permitir o compartilhamento de recursos escassos, como, por exemplo, o supercomputador ILLIAC IV, em construção na Universidade de Illinois, com o patrocínio da própria Arpa. O projeto foi amadurecendo e adquiriu momento quando a Arpa contratou Lawrence Roberts (33), do Lincoln Lab do MIT, em 1967, para tornar a idéia uma realidade. Nessa mesma época Licklider, tendo saído da Arpa em 1964, assumiu a direção do Projeto MAC no MIT.

Foi escolhido para a rede um modelo proposto por Paul Baran (34), que lançou a idéia de comunicação digital via comutação de pacotes numa série de estudos sigilosos feitos na RAND Corporation. Esses estudos foram realizados em função de um contrato com a Arpa cujo objetivo era a idealização de um sistema de comunicações que não pudesse ser interrompido por avarias locais. Nessa época a Guerra Fria estava no seu auge e a preocupação dos militares americanos era uma rede de telecomunicações que não possuísse uma central e que não pudesse ser destruída por nenhum ataque localizado. Uma conseqüência importante dessa escolha e dos desenvolvimentos posteriores é que a rede Internet herdou essa propriedade. $\mathrm{Na}$ verdade, qualquer defeito de equipamentos na rede não apenas não interrompe o seu funcionamento como adicionalmente nem chega a interromper sequer as comunicações entre processos em curso na hora da avaria, desde que permaneça em funcionamento alguma conexão física entre os dois processos. Isso resulta na robustez extraordinária da rede Internet.

Para realizar o primeiro experimento com a rede foram escolhidas quatro universidades que seriam conectadas em ja- 
neiro de 1970 na rede computacional Arpanet. Eram elas a Universidade da Califórnia em Los Angeles (centro do desenvolvimento do software), o Stanford Research Institute, a Universidade da Califórnia em Santa Bárbara e a Universidade de Utah, todos beneficiários de contratos com a Arpa. Além da comunidade acadêmica, a rede original atendia também à comunidade militar americana. A rede se expandiu rapidamente, incluindo computadores de variadas plataformas de hardware e de software, demonstrando que a comunicação e a cooperação entre sistemas até mesmo de concepções muito diferentes eram perfeitamente factíveis. Havia treze computadores na rede em janeiro de 1971, 23 em abril de 1972 e 38 em janeiro de 1973. Foi organizada a primeira demonstração pública da rede em 1972 por ocasião da "First International Conference of Computer Communications", realizada no outono de 1972. Nessa oportunidade a rede já dava suporte a um amplo conjunto de serviços regulares, entre os quais estavam incluídos o login remoto e o correio eletrônico, cujo volume de uso surpreendeu os próprios responsáveis pela rede. Ou seja, a rede estava se revelando, desde os seus primórdios, como um instrumento muito efetivo de cooperação.

As ligações da Arpanet usavam linhas telefônicas dedicadas à velocidade de 56 Kbps. Seus elementos ativos, chamados de Interface Message Processors (IMP), eram constituídos de computadores comercialmente disponíveis, cuidadosamente escolhidos para essa finalidade. Outro aspecto relevante é que a execução do projeto foi confiada a empresas particulares entre as quais deve ser mencionada a BBN (Bolt, Beranek, and Newman Inc.), de Cambridge, Mass., que era a principal executora.

É curioso notar que as empresas de telecomunicações devotaram, por muito tempo, um amplo pessimismo à técnica de comutação de pacotes, conforme relatado num artigo do principal realizador da rede Arpanet, Lawrence G. Roberts (35). Faz pouco tempo apenas que esse pessimismo foi trocado por uma participação ativa nas redes de computadores, mas mesmo hoje os serviços dessas empresas, do ponto de vista das redes de computadores, deixam muito a desejar.

\subsection{A CSnet}

O sucesso da Arpanet se propagou rapidamente a outras comunidades, que não possuíam contratos com o DoD (Department of Defense), mas desejavam participar da nova era das comunicações. Assim nasceu a CSnet, uma rede computacional relativamente barata que interligou todos os departamentos de Ciência da Computação dos EUA. A idéia nasceu em 1979 (36) sob a liderança de Lawrence Landweber da Universidade de Wisconsin, atual presidente da Internet Society. A CSnet teve amplo apoio e participação ativa da Arpa e da National Science Foundation, NSF.

Rapidamente forjou-se uma união dos departamentos interessados, elaborou-se uma arquitetura na qual as ligações da rede seriam realizadas através de serviços públicos de comutação de pacotes (Telenet e Phonenet) e estabeleceu-se uma lista de serviços de rede, pobre em relação à Arpanet, que era constituída basicamente de correio eletrônico e de transferência de arquivos. Procurou-se aproveitar ao máximo a experiência e o software já existente na Arpanet, sendo a comunicação entre as duas redes um dos objetivos básicos da experiência. A NSF acompanhou de perto o planejamento da rede e acabou se tornando o seu principal financiador por um período prefixado, após o que as universidades participantes teriam que assumir os custos. A NSF tomou mesmo uma medida inédita em relação a financiamento de quaisquer outras pesquisas: assumiu a administração centralizada do projeto por um período de dois anos para garantir que a experiência não falhasse por falta de uma coordenação central neutra.

O projeto foi definitivamente aprovado pela NSF em janeiro de 1981 e tornou-se operacional em julho de 1982. A CSnet foi um dos marcos da história das redes
35 L. Roberts, "The Arpanet and Computer Networks", op cit., p. 150

36 D. E. Comer, "A Computer Science Research Network CSnet: A History and Status Report", in Communications of the ACM, 26, 1983, pp. 747-53. 
computacionais, pois serviu para estabelecer várias novidades que viriam a influenciar o desenvolvimento da área:

- o conjunto da Arpanet e da CSnet constituiu-se na primeira rede heterogênea e pode ser considerado o precursor da Internet;

- o experimento, sendo desenvolvido no seio dos grupos de pesquisa em computação, contou com a cooperação da comunidade mais bem preparada para propor e implementar novos serviços, como um diretório único de pessoas da comunidade, novas extensões da rede, etc.;

- o experimento testemunhou o grau de adesão entusiástica de uma comunidade inteira, de alguns milhares de membros, alargando substancialmente os seus hábitos de comunicação, o que resultou num novo patamar de cooperação, levando a alguns resultados inimagináveis até então, como o estabelecimento de protocolos comuns de comunicação e o significativo nível de aproveitamento de software por grupos amplos, usando plataformas de hardware e software diferentes;

- o experimento foi instrumental no envolvimento da NSF no financiamento e administração de redes computacionais, serviu também para que a NSF pudesse acompanhar de perto o papel da rede na vida de uma comunidade científica.

Todos esses aspectos foram pioneiros e acabaram levando à constituição, logo mais, da Internet e da NSFnet, marcos obrigatórios para se chegar à situação atual.

\subsection{A Usenet}

A terceira rede que merece menção nesta retrospectiva histórica é a chamada Usenet, por suas características únicas. Trata-se de uma rede que obteve o maior número de participantes nos anos pioneiros, sem contar com nenhum tipo de subsídio centralizado. Era baseada numa arquitetura muito simples, sem precisar da comutação de pacotes, mas muito fácil de ser realizada. Oferecia apenas os serviços mais simples como correio eletrônico e transferência de arquivos. A rede levou ao estabelecimento de um novo serviço, o News ou a conferência mundial, que se tornou muito popular e que existe até hoje.

A Usenet era baseada no programa uucp (Unix to Unix copy) que vinha incluído em todos os sistemas Unix, cuja popularidade crescia exponencialmente nessa época. Esse programa nada mais é do que a cópia de arquivos entre sistemas remotos. As ligações eram feitas por linha discada, usando modems de 300 a 2400 bps, em horários predeterminados, quando dois computadores trocavam as suas informações. Para se conectar à rede tudo que era necessário era um computador rodando Unix com acesso a um modem, uma linha discada e de um amigo ou organização dispostos a servir de ponto intermediário de comunicação. Assim, a rede cresceu de forma absolutamente descentralizada, anárquica mesmo, chegando a centenas de milhares de usuários em 1986(37). Essa rede iniciou-se por volta de 1978 e posteriormente a arquitetura foi aproveitada para formar uma das primeiras redes européias, a Eunet.

\subsection{Nascimento da Internet}

Três fatos muito importantes devem ser mencionados neste ponto. De um lado temos a implementação de toda a pilha de protocolos TCP/IP da Arpanet, na versão do Unix escrito em Berkeley, a "Berkeley System Distribution” (BSD). Este sistema era distribuído gratuitamente para universidades e rodava na arquitetura Vax da Digital, a mais popular em universidades na época. Posteriormente ela deu origem a SunOS, também muito popular em ambientes acadêmicos, ligados às redes então existentes. A inclusão desse software num sistema operacional de ampla distribuição foi um fato catalisador que levou ao estabelecimento do TCP/IP como um padrão de fato. O sucesso desse padrão forçou a adesão da Microsoft em 1995, e a partir daí a inclusão desta pilha de protocolos em sistemas operacionais é praticamente obrigatória, sob pena de alto risco de falência do empreendimento. 
O segundo fato que merece menção é o surgimento da empresa SUN que aproveitou os projetos da Stanford University Network e que foi fundada por entusiastas de grande visão da Universidade de Stanford e da Universidade de Berkeley, em 1982. A SUN popularizou o sistema operacional Unix, versão BSD, e facilitou sobremaneira a utilização de computadores em redes locais baseadas nos protocolos TCP/IP. Essa política fazia parte da filosofia da empresa, que professava nos anos 80 que "the Network is the computer" numa espécie de reformulação do lema "a união faz a força”. Um dos instrumentos mais poderosos da empresa nesse sentido foi a introdução do Network File System (NFS), baseado num protocolo que a empresa tornou público e que teve uma aceitação universal logo em seguida. A NFS permite o compartilhameto transparente dos discos de vários computadores numa rede local facilitando a visão da rede heterogênea como um único sistema pelo usuário.

O terceiro fato a ser mencionado é a criação, em 1984, de outra empresa, a Cisco, por gente que igualmente saiu da Universidade de Stanford. Essa empresa escolheu como missão a fabricação de elementos ativos para a rede Internet, isto é, computadores especializados que tratam do encaminhamento, pela rede, dos pacotes digitais. Os mais complexos desses equipamentos são os roteadores que substituíram os computadores especializados originais, chamados de Interface Message Processors (IMP). A fabricação de hardware especializado para o protocolo TCP/IP tem duas conseqüências importantes. Por um lado, ele aumenta muito a eficiência do processo de roteamento dos pacotes, permitindo que a rede alcance patamares de eficiência substanciais. Por outro lado, a fabricação em grande escala implica num barateamento dos equipamentos. Tudo isso transformou a Cisco numa empresa gigante que fatura quatro bilhões de dólares por ano e a Internet numa rede que conta hoje (julho de 1997) com mais de dezesseis milhões de computadores.
Nos anos intermediários da década de 1980 houve uma proliferação de redes (38) tais como Decnet, Vnet, Bitnet, Hepnet, Janet, Junet, Earn, Netnorth, Fidonet, etc. O livro de Frey e Adams (39), editado em 1989, listava nada menos do que 105 redes espalhadas pelo mundo todo, várias delas com uma forma particular de endereçamento de $e$-mail.

Nessa época a rede Arpanet começou a mostrar sinais de fadiga devido à baixa velocidade de suas linhas (56 Kbps). Dado o enorme interesse, agora de toda a comunidade acadêmica, na conexão à rede, a NSF iniciou em 1987 um investimento maciço no estabelecimento de uma ampla rede acadêmica de alta velocidade e que interligasse inclusive os seus centros de supercomputação com toda a comunidade consumidora desse recurso. Criou-se a rede acadêmica NSFnet que viria a absorver a Arpanet, desativada em 1990. Nessa época a NSFnet alcançava toda a comunidade acadêmica dos EUA com um backbone de velocidade 1,5 Mbps. A NSFnet, sendo uma rede acadêmica, regia-se por uma Acceptable Use Policy que definia os usos aceitáveis e inaceitáveis da rede. A rede, sendo financiada pela NSF, não podia ser usada para fins lucrativos. Vale mencionar que a NSF executou e operou a sua rede através de empresas privadas, sendo a empresa Merit, ligada à Universidade de Michigan, uma das principais contratadas. Maiores detalhes sobre a história da NSFnet podem ser encontrados em Frazer (40).

Com a proliferação das redes, o modelo e protocolos TCP/IP emergiram como o padrão predominante da área e isso tornou muito fácil a interligação de redes independentes. A megarrede resultante chamou-se de Internet, que nasceu sem alardes como um corolário natural da Arpanet e da NSFnet (41). A Internet até hoje não tem um órgão regulamentador oficial. O que existe, desde 1992, é a Internet Society, uma sociedade civil que talvez assuma o gerenciamento global da rede em algum momento no futuro. A situação atual lembra talvez a anarquia da Usenet nos anos 80 , descrita pouco acima.

\footnotetext{
38 Idem, ibidem.

39 D. Frey and R. Adams, !\%@: A Directory of Electronic Mail Addressing and Networks, Sebastopol, CA, O'Reilly \& Associates, Inc., 1989.

40 K. D. Frazer, "NSFnet: A Partnership for High-speed Networking, Final Report 1987-1995", Merit Network Inc., 1996.

4| A primeira referência que conhecemos à palavra Internet ocorre na RFC 675 de Iㅇ de dezembro de 1974 .
} 
Apesar dessa situação, o que mantém a Internet como uma unidade é o protocolo TCP/IP e o mecanismo público de fixação de suas normas através dos chamados RFC (Request for Comments), cuja aderência rigorosa é forçada pelo desconforto, que se manifestaria em dificuldade de comunicação com o resto do mundo, de quem queira, porventura, se afastar. Em outras palavras, o volume da Internet no momento é tal que se torna impossível qualquer tentativa de concorrência com ela. É impossível exagerar, com relação a esse aspecto, a importância da adoção do protocolo TCP/IP pela NSFnet em 1987. A própria indústria de hardware incorporou esse protocolo nos seus produtos e, hoje em dia, a montagem de uma rede computacional fora dos padrões TCP/IP provavelmente seria proibitiva em função do seu alto custo e baixa probabilidade de aceitação. Como consequiência dessa situação as muitas redes que existiam ainda cinco anos atrás vêm desaparecendo uma a uma, sendo absorvidas pela Internet. Todas as tecnologias proprietárias encaixam-se nessa descrição.

A ampla disponibilidade de hardware TCP/IP relativamente barato e a ampla disponibilidade do software de rede TCP/IP, praticamente gratuito, levam ao estabelecimento cada vez mais numeroso de redes corporativas, sem interesse de conexão à rede Internet, por questões de segurança empresarial, que usam a mesma tecnologia, o mesmo hardware e o mesmo software da Internet. Essas redes, que estão revolucionando a vida interna das grandes empresas (42), vêm sendo chamadas de Intranets desde o início de 1996 (43).

A NSF percebeu que a rede construída excedia rapidamente o seu interesse e o seu potencial de financiamento e que, vencida

42 I. Martin, Cybercorp, the New Business Revolution, New York American Management Association, 1996

43 R. Bernard, Corporate Intranet, John Wiley \& Sons, Inc., 1996.

44 T. Berners-Lee, R. Cailliau, A Loutonen, H. F. Nielsen, and A. Secret, "The World-Wide Web", in Communications of the ACM, 37, 1994, pp. 76-82
Esta transição veio a ser conhecida como a “privatização" da Internet.

A resposta da comunidade mundial foi imediata, explosiva e até surpreendente. $\mathrm{O}$ uso da rede aumentou para patamares nunca antes imaginados e continua crescendo no seu ritmo exponencial.

\subsection{Nascimento da teia mundial}

Até pouco mais de três anos atrás os aplicativos principais da rede Internet eram o correio eletrônico, o serviço de News, o login remoto em qualquer máquina da rede e a transferência de arquivos. Tudo isso mudou com o aparecimento e popularização da World Wide Web, a partir de 1994. Essa teia mundial entrou com um crescimento exponencial de velocidade nunca antes visto, nem mesmo na área da computação, e hoje domina, com facilidade, as outras aplicações que, aliás, foram todas incorporadas a ela. A utilização dos paradigmas de hipertexto, multimídia, arquitetura cliente/ servidor e comunicação segura, aliados a uma interface agradável e lúdica, fácil de ser aprendida e usada, e aliados também a uma enorme facilidade de disponibilização de informações na teia, revolucionou a própria revolução da "sociedade da informação".

Os dois nomes mais associados ao fenômeno da teia são o do físico suíço Tim Berners-Lee, que liderou a partir de 1990 a implantação da WWW nos laboratórios da Cern em Genebra, Suíça (44), e do então estudante de computação Marc Andreessen que, no laboratório de supercomputação da Universidade de Illinois, desenvolveu o visor (browser) Mosaic em 1993, levando a um novo patamar a facilidade e versatilidade de uso do sistema. Em 1994 Andreessen deixou a universidade para ser um dos fundadores da empresa Netscape, que hoje domina o mercado de software dos aplicativos para a Internet com um conjunto de produtos liderados pelo visor que herdou e desenvolveu as propriedades e funcionalidades do Mosaic. Outra característica desse visor é que ele é disponível 
para praticamente todas as plataformas de hardware e de software, e assim ele transforma o computador numa verdadeira máquina Netscape com uma interface de uso independente da plataforma utilizada. Isso contribui ainda mais para a universalização dessa interface.

Outro fenômeno que faz jus à menção neste histórico é o surgimento do sistema de indexação Alta Vista (45) em dezembro de 1995. Ele memoriza a parte pública da teia, através da visitação periódica de todas as páginas atingíveis por um robô (31 milhões de páginas em julho de 1997, localizadas em 627.000 servidores), e efetiva uma indexação muito engenhosa e eficiente do material levantado. A partir desses dados um computador localizado nos laboratórios da Digital em Palo Alto responde instantaneamente a mais de 31 milhões de perguntas diárias (360 perguntas a cada segundo, dia e noite), vindas do mundo inteiro.

Uma pergunta típica seria qual o conjunto de páginas da teia mundial que contêm as palavras “Tom Jobim" uma perto da outra. A resposta instantânea chega como uma lista de tantos apontadores, quantas páginas encontradas (490, no caso), cada uma trazendo o título, o endereço e as primeiras palavras da página referenciada. Com um clique do mouse acessa-se a página propriamente dita, qualquer que seja a sua localização no globo terrestre. Em outras palavras, o Alta Vista instantaneamente coloca a teia inteira na ponta dos dedos de qualquer um que saiba fazer uma pergunta adequada e bem formulada. Não é necessário dizer que o serviço foi um sucesso instantâneo.

\subsection{História das redes no Brasil}

À guisa de epílogo, adicionamos alguns dados sobre a história das redes no Brasil. A nosso ver o responsável pioneiro pelo rápido progresso inicial das redes no Brasil foi o professor Oscar Sala, da Universidade de São Paulo, único ex-presidente tanto da Sociedade Brasileira para o Progresso da Ciência quanto da Academia Brasileira de Ciências. Ele fez chegar ao Brasil a rede Bitnet em fins de 1988, conectando a Fapesp ao Fermilab nos EUA, através de uma linha dedicada de velocidade $4.800 \mathrm{bps}$, alugada da Embratel. Nessa linha coexistiram várias outras redes também, como a Hepnet, a Decnet, a Usenet e finalmente a própria Internet.

Na época, o professor Sala era o presidente do Conselho Superior da Fapesp e, nessa qualidade, ele foi instrumental para interessar aquela Fundação em dar um apoio decisivo às redes e um incentivo a toda a comunidade acadêmica do país na adoção desse recurso. Isso foi feito através do financiamento da ligação das instituições acadêmicas paulistas à rede ANSP (Academic Network at São Paulo) e através da facilitação da ligação à rede de outras instituições acadêmicas no país, franqueando a todos o uso acadêmico da linha internacional mantida pela Fapesp. Essa postura da Fapesp levou a uma rápida e entusiástica adoção da nova cultura em especial nas três universidades paulistas que, por sua vez, começaram a investir na disponibilização dos recursos às suas respectivas comunidades.

A ligação da Fapesp não foi a primeira conexão de rede a chegar ao Brasil. Ela foi precedida pelo Laboratório Nacional de Computação Científica do CNPq que alugou uma linha da Embratel três meses antes da Fapesp, ligando-se à Bitnet. Mas essa linha, embora muito importante, não teve o mesmo impacto da iniciativa da Fapesp. A ligação do LNCC não evoluiu com o tempo e foi desativada com a mesma velocidade inicial de 9.600 bps, em 1996, quando da desativação da rede Bitnet no Brasil.

Outra ligação pioneira que deve ser mencionada é aquela realizada pela rede Alternex, ligada ao Ibase, uma organização não-governamental que se ligou à rede Usenet, via linha discada internacional, em julho de 1989.

Em retrospecto, o evento de maior relevância para o Brasil foi a nossa ligação à Internet. A primeira ligação nacional em TCP/IP foi realizada pela Fapesp em fevereiro de 1991. A Fapesp conseguiu
45 R. Seltzer. E. Ray, and D. S. Ray. The AltaVista Search Revolution, op. cit. 
disponibilizar o TCP/IP no seu Vax, e se encarregou da administração do domínio br e da distribuição dos números IP em todo o país, áreas em que colabora com o Comitê Gestor da Internet/BR até hoje.

Alguns meses depois, ainda em 1991, estabelece-se outra linha internacional, ligando o Rio de Janeiro à Internet, com origem no Núcleo de Computação Eletrônica da UFRJ. Essas ligações pioneiras foram instrumentais para a aceitação do padrão TCP/IP no Brasil. Na verdade, nessa época, era objeto de discussão ativa o protocolo que seria mais adequado para ligar o Brasil nas redes internacionais.

Deve ser mencionada também a dificuldade substancial que todos tiveram para interessar a Embratel nessas primeiras ligações internacionais. Uma outra dificuldade era causada pela política de reserva de mercado, vigente na época. Essa política dificultava o acesso brasileiro ao sistema operacional Unix e às estações de trabalho que se revelaram, a posteriori, como os meios mais ágeis de viabilizar e disseminar a cultura Internet no país. Vale a pena registrar que a quase totalidade da nossa comunidade teve o seu primeiro contato com o Unix a partir de 1990, quando se iniciou o relaxamento da reserva de mercado, sendo bastante raros os casos de estações de trabalho, quase sempre solitárias e compartilhadas por comunidades numerosas, operando em 1988 ou 1989.

O $\mathrm{CNPq}$ se interessou pelas redes computacionais a partir de julho de 1989 , quando foi lançada a Rede Nacional de Pesquisas (RNP) na feira da Sucesu, sem estrutura física própria na época. O backbone nacional da RNP começou a ser instalado em 1991, com linhas de 9.600 bps. Hoje, as linhas principais da RNP têm velocidade de $2 \mathrm{Mbps}$. Até agosto de 1996 a ligação da RNP ao exterior era feita através das linhas mantidas pela Fapesp; nessa data a RNP obteve uma linha própria que ligava o Distrito Federal aos EUA.

Com a posse do governo Fernando Henrique Cardoso, em 1995, estabeleceuse o Comitê Gestor da rede Internet no Brasil, com a atribuição de coordenar e incentivar a implantação dessa rede no país. Paralelamente, a RNP decidiu tornar-se uma rede mista que, além do tráfego acadêmico, carregava também tráfego comercial. Assim, ela passou a constituir a espinha dorsal da rede Internet no Brasil. Até hoje, o backbone da RNP é o único de alcance nacional no país. Ele foi e continua sendo instrumental para o acentuado progresso da Internet no Brasil. Maiores informações sobre a situação e evolução da Internet no Brasil podem ser encontradas no servidor do Comitê Gestor (46).

Deve ser destacada também a espiral de Campos (47), uma contribuição de Ivan Moura Campos à conceituação do desenvolvimento da Internet em espirais. Isso compreende ciclos que se iniciam em pesquisa e desenvolvimento, passam por parcerias governamentais e depois por parcerias privadas para chegar como uma commodity à sociedade, antes de recomeçar o próximo ciclo.

\section{ASPECTOS DO IMPACTO}

Se nos basearmos no que é possível entrever hoje, fica claro que o impacto da revolução informática em todos os aspectos da atividade humana tem o potencial de ser muito grande e de provocar mudanças muito profundas. Entretanto, em uma situação de mudanças rápidas e muitas vezes imprevisíveis, como a que vivemos hoje, é extremamente difícil determinar a natureza exata e detalhada do impacto da entrada em uso das novas tecnologias sobre cada aspecto dessas atividades. Nessa situaçãoé inevitável que existam controvérsias sobre o futuro da área (48).

Apesar de o computador pessoal já existir há anos, sendo hoje, pelo menos nos países mais desenvolvidos, um eletrodoméstico como qualquer outro, a introdução do outro elemento crucial do sistema, a rede mundial Internet, no sentido da sua abertura para uso fora do meio acadêmico, ocorrida há apenas dois anos, é muito recente e interage fortemente com o primeiro, de forma que não se pode dizer que as conse- 
qüências da introdução das novas tecnologias de computação e comunicação já tenham se desenvolvido e estabelecido completamente (49).

No meio acadêmico a disponibilidade tanto de computadores poderosos quanto de redes computacionais significativas precede em vários anos sua disponibilidade pela sociedade em geral. De fato, o meio acadêmico foi o berço original de ambos esses universos tecnológicos. Entretanto, mesmo no meio acadêmico o impacto dessas tecnologias ainda está longe de sua realização completa, e existem alguns aspectos cuja introdução ainda é muito recente, mesmo nesse caso.

Devemos ter em mente que as reações sociais e culturais à introdução de tecnologias completamente novas como essas têm velocidade limitada pelas características e ritmos biológicos e psicológicos do ser humano. De forma muito grosseira, para a adaptação a fenômenos como a revolução informática, a qual envolve mudanças significativas na educação do indivíduo, pode-se avaliar que o tempo de resposta típico seja da ordem do tempo do ciclo de educação do indivíduo, ou seja, cerca de uma e meia a duas décadas. No meio acadêmico, no qual a curiosidade e a flexibilidade intelectual são requisitos básicos, esse tempo deverá ser mais curto, mas mesmo assim não menor do que alguns anos.
Estamos hoje na desconfortável situação de nos encontrar, surpreendentemente, bem no meio deste complexo e inesperado processo e, apesar de sua magnitude e suas formidáveis potencialidades serem claramente aparentes, estamos talvez excessivamente envolvidos para poder ver com clareza e, muito menos, prever o que se seguirá com qualquer tipo de segurança.

Assim, o que podemos fazer com alguma segurança é listar as mais notáveis características da nova tecnologia e apontar os possíveis impactos que poderão ter, chamando a atenção, sempre que possível, para os indícios já existentes de sua realização. Procuraremos nortear nossa avaliação dos impactos por meio da informação disponível sobre os impactos que já estão razoavelmente bem caracterizados no meio acadêmico. Entretanto, deve-se manter em mente que os impactos sobre a sociedade em geral poderão ser quantitativa e qualitativamente diferentes destes.

Resumindo os aspectos técnicos principais, a rede computacional internacional, com seus protocolos universais abertos e extremamente flexíveis, aliada à existência de microcomputadores poderosos nas pontas de cada ramificação capilar, uma vez que a rede esteja completamente capilarizada, alcançando a casa de qualquer cidadão que queira utilizar seus serviços, constitui um meio de comunicação completamente novo. Este novo instrumen-
49 R. Kraut, "The Internet@Home", op. cit.

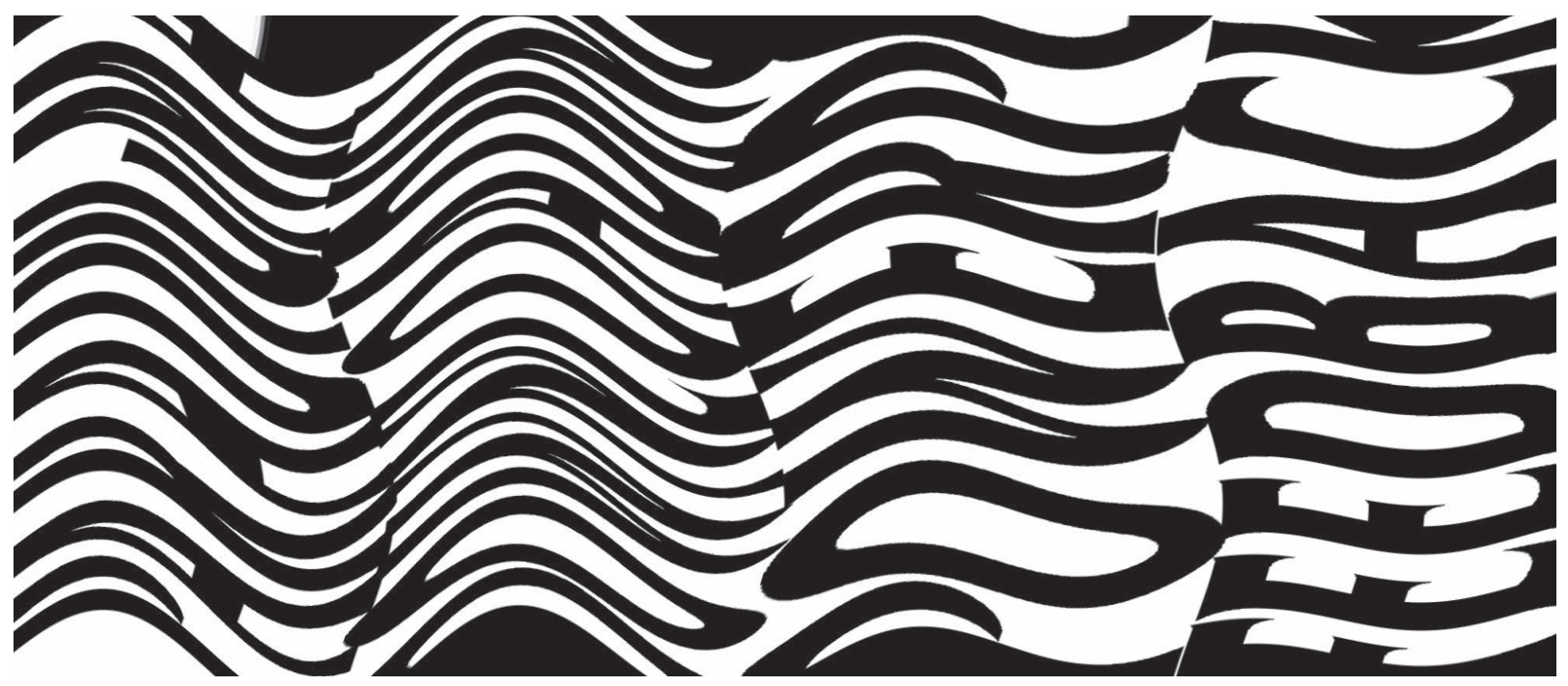


to da civilização apresenta inacreditável eficiência no compartilhamento dos meios de comunicação, efetivamente zera as distâncias entre os habitantes do planeta e permite o acesso, a transmissão e a replicação exata de quantidades praticamente ilimitadas de informação, que são mantidas de forma distribuída por toda a rede, podendo entretanto ser indexadas e relacionadas, através da própria rede, para facilidade de localização. Ademais, o novo instrumento, devido à sua eficiência e à facilidade de comunicação que permite, é um catalisador efetivo na cooperação entre entes, mesmo que distantes; uma realidade impossível de ser alcançada antes do seu advento.

Qual a relação entre isso tudo e o desenvolvimento do país? A importância da ciência em geral e também da revolução da informática para o desenvolvimento tem dois aspectos principais: a mudança de fatores econômicos e a mudança da cultura e das mentes das pessoas que a compõem. A revolução informática tem amplo potencial para mudar de forma profunda esses aspectos. Essas mudanças básicas, por sua vez, tornam inevitáveis mudanças sociais, políticas e legais a elas relacionadas.

\section{I. Preliminares acadêmicos}

Começamos por mencionar alguns impactos das novas tecnologias no meio acadêmico.

Um dos primeiros efeitos da tecnologia foi a viabilização de cooperação científica a distância de uma forma muita mais efetiva. Basta o correio eletrônico para que seja possível desenvolver trabalhos em cooperação através da rede entre pesquisadores que já se conheçam pessoalmente e que possam esporadicamente se reencontrar. $\mathrm{O}$ ritmo de desenvolvimento pode cair um pouco se os pesquisadores estiverem em fusos horários diferentes, e também devido à necessidade de se digitalizar todas as conversas, argumentos e discussões técnicas. Entretanto, apesar desses desconfortos, passar a ser possível na prática trabalhar dessa forma, e assim alguns trabalhos são feitos, que de outra forma talvez não fosse possível. A transmissão de vozes e vídeo pela rede poderá ter um impacto ainda maior, permitindo que o processo de implantação desse estilo de trabalho avance muito mais, por tornar o trabalho mais confortável.

Outro impacto do correio eletrônico é a submissão eletrônica de trabalhos para publicação, o que já está sendo feito de forma rotineira por uma grande quantidade de revistas especializadas. Isso tem levado ao surgimento de revistas especializadas completamente eletrônicas, que prescindem completamente da publicação em papel. De fato, cessa a necessidade de publicação em papel como verdadeira forma de disseminar o resultado de pesquisas, e de outras formas de informação nas quais o que interessa é mais a velocidade de acesso à informação e não tanto a longevidade do registro permanente da informação. Isso está forçando uma revisão do conceito de publicação científica (50).

Um aspecto no qual a WWW tem um grande potencial de impacto é a publicação pela rede de dados dos mais variados tipos. Nos grandes experimentos, está se tornando rotina a disponibilização de acesso não apenas ao resultado de uma ou outra análise dos dados, mas aos dados na íntegra, em formato digital, acessíveis para análise por qualquer um que tenha acesso à rede. Também se pode citar nessa categoria a colocação de acervos de museus científicos em bancos de dados acessíveis pela rede, incluindo, por exemplo, dados e fotos de espécimes biológicos. Esses bancos facilitam a preparação de viagens de estudos, com acesso preliminar às espécimes ou dados, e podem mesmo substituí-las, em alguns casos. Há também a disseminação de resultados de programas para modelamentos de variados tipos, por exemplo, de dinâmica atmosférica, que são de interesse mais geral e não puramente para a pesquisa.

Um impacto importante da revolução informática nas ciências naturais, que contribui muito para o desenvolvimento des- 
tas, é aquele proporcionado pela computação especializada de alto desempenho, e pelo aumento exponencial do desempenho dos sistemas computacionais em geral. Ele tende a ocorrer num prazo menos imediato, mas pode ser muito profundo. Algumas áreas na qual ele é importante são a física de sistemas complexos, a biologia e bioquímica do DNA e a química computacional.

A revolução do microcomputador, acoplada com a revolução das redes, está começando a se fazer sentir mesmo no mundo especializado dos computadores de desempenho extremamente alto. Os grandes e caríssimos supercomputadores de outrora, fabricados especificamente para esse fim, estão começando a ser substituídos por redes de microcomputadores extremamente rápidos interligados por redes de pequena extensão e velocidade extremamente alta, da ordem de Gbps.

Hoje, a CPU do mais rápido supercomputador existente não chega a ser três vezes mais veloz do que o mais rápido microprocessador produzido em massa (51), enquanto a velocidade das redes especializadas de pequena extensão utilizadas para interligar as memórias desse microprocessador, com velocidades acima de $1 \mathrm{Gbps}$, já representa uma fração apreciável da velocidade de comunicação interna entre o processador e a sua memória.

Assim, não é tão surpreendente que computadores paralelos formados por redes rápidas com um grande número de microprocessadores possam alcançar e até mesmo superar o desempenho dos supercomputadores tradicionais. De fato, a máquina mais rápida em funcionamento hojeé um computador construído pela Intel para o governo norte-americano, que é constituído de mais de 7.000 processadores Pentium, como os que podemos ter em casa em um computador pessoal.

O impacto da revolução da informática nas atividades de pesquisa do mundo acadêmico se acopla a outro impacto profundo e de prazo longo, o impacto sobre a educação. Apesar de já serem usados computadores em rede para fins educativos em muitos lugares, ainda é cedo para avaliar este impacto no mundo acadêmico, pois um dos fatores mais importantes para isso deverá ser a WWW, cuja introdução é muito recente. De fato, os ventos mais fortes de mudança vêm dos jovens, e nem tanto de seus professores. São os jovens que estão mais envolvidos na revolução, tanto como realizadores das façanhas técnicas quanto como vetores das novas tecnologias. Talvez seja necessário esperar pela nova geração de professores, que chegue ao mercado de trabalho já completamente informatizada, para que o impacto na educação se faça sentir com força total.

Concluímos comentando sobre o papel das universidades, que até agora têm atuado tanto como inventoras e formadoras da cultura quanto como as maiores consumidoras das novas tecnologias, nesta revolução. A tecnologia que propulsiona a revolução é recente, foi desenvolvida nas últimas décadas. Tanto o projeto quanto a construção contaram com grande contribuição da comunidade acadêmica. Talvez a maior contribuição das universidades tenha sido a de serem os usuários-cobaia do sistema, estabelecendo novos paradigmas para o uso do recurso.

Tratando-se de uma comunidade ávida por novidades em geral e sem medo de explorar o desconhecido, o desenvolvimento desses paradigmas foi muito rápido, e possivelmente profundo, e resultou um conjunto de tecnologias de hardware e software muito fácil de ser usado e assimilado pela sociedade em geral, processo este que está em curso desde 1994 quando da permissão da comercialização da rede, que operava com fortes restrições de acesso até aquele momento. Os novos paradigmas de armazenamento, troca e compartilhamento da informação são capazes de mudar hábitos muito básicos, como por exemplo o funcionamento de editoras e jornais, o advento do home-banking, o advento da biblioteca digital, o advento da educação a distância, a possibilidade de operar serviços de telefonia através da Internet e a distribuição de software.
5। +. Dongarra, Performance of Various Computers Using Standard Linear Equations Software, 1996. http:// www.netlib.org/benchmark/ performance.ps. 


\subsection{Aspectos culturais}

Uma das formas de se analisar a extensão da influência de uma nova tecnologia sobre a cultura da sociedade é através de sua influência visível na linguagem falada por esta sociedade. Existe a possibilidade de que a Internet venha a ter um papel importante no estabelecimento de uma língua universal no planeta Terra, provavelmente alguma forma de inglês. Hoje é comum que jovens universitários, apesar de não falarem essa língua, sejam capazes de ler e escrever razoavelmente bem nela, devido ao seu contato constante com a rede. Com a disponibilização de forma rotineira da transmissão de serviços de telefonia de áudio e vídeo pela rede, além da linguagem escrita, é possível que a capacidade de entender e falar a língua venha a se adicionar a estas num futuro próximo.

Uma provável tendência que a rede mundial poderá ter, e que talvez deva ser encarada mais como um perigo, é a tendência para a monocultura. Em termos da influência cultural da rede, os ventos sopram muito definitivamente dos países do Primeiro Mundo, em particular dos EUA. Poderá acontecer uma excessiva homogeneização das culturas dos muitos povos diferentes que participam do que costumamos chamar de civilização ocidental? Ou mesmo da cultura de todos os povos que tiverem acesso amplo a esse novo aspecto do ambiente do planeta?

Isso poderia ter conseqüências muito sérias, em primeiro lugar porque pode dar origem a reações violentas, mas não menos porque a perda da capacidade da espécie de experimentar com culturas diferentes é uma perda de diversidade que, assim como a perda de diversidade biológica em ecossistemas, pode levar a processos degenerativos e eventualmente à extinção. Temos bons motivos para temer essa possibilidade, entretanto se a aceitarmos como provável poderemos estar dando ao ser humano menos crédito do que ele merece. É perfeitamente possível que as culturas mudem e se adaptem ao novo ambiente, sem contudo desaparecer. É até possível que novas culturas acabem emergindo como resultado desse processo. Mas o debate, por ora, fica necessariamente aberto sobre se a introdução das novas tecnologias irá, a longo prazo, empobrecer ou enriquecer a civilização que conhecemos hoje.

De qualquer forma é inevitável que estejamos desenvolvendo uma visão do futuro segundo a qual estamos caminhando a passos largos para o estabelecimento de uma "sociedade da informação" no terceiro milênio. Essa ampliação do escopo daquilo que foi desenvolvido no meio acadêmico pode levar à perda ou atenuação da tradição de cooperação e liberdade de informação que caracterizou o início da Internet: só o futuro poderá esclarecer essa questão.

\subsection{Aspectos econômicos}

A informática moderna tem um papel óbvio na produção industrial, que já é importante há algum tempo. Como um exemplo claro disso, podemos citar os sistemas de CAD (Computer Aided Design) e CAM (Computer Aided Manufacturing), que são amplamente utilizados na indústria. O impacto da informática sobre os meios produtivos é, portanto, mais imediato e também potencialmente mais doloroso, obrigando a sociedade a adaptações rápidas, como, por exemplo, o caso do deslocamento de mão-de-obra industrial pela produção robotizada através de CAM. Entretanto, não é só na indústria que a informática pode ter um impacto econômico considerável. Sua importância é grande também na agricultura, por exemplo para a previsão de tempo, uma atividade na qual tanto a rede de comunicação quanto a computação de alto desempenho são de importância capital.

O uso amplo de meios informáticos na indústria, tanto diretamente na produção quanto na administração, é tão importante que pode ser caracterizado como uma nova revolução industrial. As novas tecnologias permitem uma automação inteligente de processos, passível de controle fino por meio de programação. Com a rede internacional e a WWW, passam também a estar disponíveis novas formas de propaganda e 
de pesquisa de mercado, muito mais eficientes e flexíveis que as atuais, que podem ter um grande impacto sobre o sistema produtivo. A produção automatizada e a comunicação e cooperação das empresas produtoras com o público de consumidores, através da nova rede internacional, combinam-se para dar origem a possibilidades verdadeiramente fantásticas.

Por um lado, a produção automatizada permite não só a produção em massa de bens, como também um maior grau de personalização e variedade dos produtos, pois não é mais necessário retreinar um corpo de trabalhadores quando se muda o item a ser produzido, nem é mais necessário reconstruir uma linha e metodologia de produção. Todas essas mudanças passam agora a se realizar no âmbito de um programa de computador, e a administração da produção passa a ser um problema de programação. É concebível que as fábricas possam ser completamente representadas por programas que simulem sua ação, e que a criação e o teste de programas para a produção de novos produtos possam ser realizados por meio de tais simulações.

Por outrolado, os consumidores podem agora realizar as compras através da rede, utilizando a WWW, e pelo mesmo processo podem suprir os fornecedores de informação detalhada sobre suas preferências. Com o aparecimento de shopping pela WWW, podemos fazer supermercado sem sair de casa, simplesmente clicando o mouse em produtos ao longo das prateleiras de um supermercado virtual, ao mesmo tempo em que podemos obter informação detalhada sobre cada produto (52).

O feedback produzido pelas próprias aquisições realizadas e por mensagens enviadas pelos consumidores, que podem agora ser monitorados em detalhe, pode ter um efeito muito mais imediato sobre a produção e distribuição de muitos produtos. Em alguns casos, quando o conteúdo do produto adquirido é algum tipo apropriado de informação, a própria entrega dos produtos pode ser feita imediatamente por down-loading através da rede, como, por exemplo, no caso de software, livros em forma eletrônica, gravações musicais e gravações de vídeo.

As novas tecnologias de computação e comunicação e os novos métodos de manipulação de informação a que eles dão origem têm o potencial de mudar de forma profunda as sistemáticas de produção e distribuição de produtos ora existentes. Ao mesmo tempo, eles têm o potencial de provocar instabilidade social, pelo menos durante algum tempo, por exemplo pelo alijamento de mão-de-obra de nível educacional mais baixo, e devido à necessidade de retreinamento de funcionários e mesmo dos consumidores.

Por outro lado, o próprio funcionamento da rede é um negócio de bilhões de dólares anuais envolvendo empresas de telecomunicações, provedores de acesso, especialistas em projeto de páginas, etc., gerando novas necessidades no mercado de trabalho. Um exemplo seria a nova profissão de "minerador de informações", um especialista que pudesse localizar na rede informações sobre um tema específico e pudesse editá-las e reorganizá-las para posterior utilização por um cliente.

Um aspecto econômico interessante é a questão de quem arca com os custos da própria Internet. Até agora, como se tratava de uma rede acadêmica voltada para a pesquisa, os custos eram distribuídos entre universidades, institutos de pesquisa e agências financiadoras. Como se tratará essa questão em uma rede universal pesadamente usada para fins comerciais? Idealmente cada usuário pagará pelo seu próprio uso do serviço, mas no momento, não temos tecnologia para contabilizar de forma detalhada o uso da rede, e o estabelecimento dessa tecnologia provavelmente exigirá intenso investimento. Exigirá também um consenso bastante amplo quanto ao modelo a ser adotado para tal contabilidade. Maiores informações podem ser obtidas na própria teia (53).

\subsection{Aspectos sociais e políticos}

Quais podem ser as conseqüências da absorção de um objeto completamente novo

\footnotetext{
52 Amazon.com Books. http:// unw.amazon.com/. CDnow: Main: Homepage. http:/ www.cdnow.com/. Leite fazenda - menu. http:// www.leitefazenda.com.br menu.htm. Bem-vindo ao Pão de Açúcar. http:// muw2.uol.com.br/pda/. Virtual Vineyards. http:// www.virtualvin.com/.

53 Millicent. http:// www.research.digital.com/ SRC/millicent/. The Information Economy. http: /www.sims.berkeley.edu/ resources/infoecon/
} 
e tão complexo, como este, pela sociedade? Certamente podemos esperar mudanças de comportamento, e o perigo de instabilidade causada por mudanças muito rápidas. Entretanto, é muito difícil prever com segurança as possíveis conseqüências do processo para sabermos que cuidados tomar. É argumentável que exista um limite mínimo de tempo para a consolidação social de revoluções tecnológicas profundas, baseado no tempo típico de mudança das gerações no controle dos assuntos da sociedade, entretanto esta é uma mudança que poderá muito bem acontecer muito perto deste limite mínimo.

Algumas das possíveis consequiências sociais advêm simplesmente das novas possibilidades de comunicação e de cooperação que passam a existir. Por exemplo, passa a existir a possibilidade de que qualquer indivíduo possa transmitir informação para um número ilimitado de outras pessoas, através de broadcasting na rede, a custos muito baixos. Este é um privilégio que até agora só estava ao alcance dos indivíduos política ou economicamente poderosos.

Por outro lado, é claramente impossível que todos os participantes sejam ouvidos nestes broadcastings, pois isso levaria imediatamente a uma enorme sobrecarga de informação chegando a cada um dos ouvintes. Que mecanismos surgirão para definir quem é ou não é de fato ouvido? Como cada participante decidirá o que ouvir e o que ignorar dentro da massa de dados que atingirá a todos pela rede, seja por brodcasting ou simplesmente pelo imenso volume da informação disponível quando requisitada pelo participante, numa constante information overload? Será necessário que apareça a figura do information manager como uma nova profissão, ou como um novo serviço através da própria rede? Até que ponto essas tarefas poderão ser feitas automaticamente, por programas de computador?

Devido ao efeito das novas tecnologias sobre os meios produtivos, haverá uma mudança qualitativa e quantitativa na demanda por educação. Hoje em dia, vários setores requerem de seus empregados "conhecimentos básicos de informática”. Trata-se de um segundo nível de alfabetização, com o tempo não será mais suficiente saber ler e escrever. As dificuldades atuais para se dar ensino amplo e de qualidade tendem a aumentar à medida que o patamar mínimo de qualidade aceitável sobe.

As mesmas tecnologias que originam esses problemas podem vir a trazer sua solução. Novos métodos envolvendo ensino assistido por computador estão sendo tentados e podem vir a modificar profundamente o processo educacional. Sendo a educação das novas gerações uma das principais atividades de qualquer sociedade civilizada, e também uma das mais custosas e difíceis, qualquer impacto positivo que as novas tecnologias possam ter sobre os processos e métodos educacionais é de extrema importância. Como a educação sempre se realiza em prazos longos, a transição dos velhos métodos para os novos pode se mostrar muito lenta se comparada com o crescimento vertiginoso da informatização, e o período de transição pode alienar toda uma geração, com o risco de criar uma verdadeira bomba social. Certamente um aspecto importante é o papel das novas tecnologias como ferramentas de integração mundial. Com o crescente estabelecimento da aldeia global, já existe hoje o desafio aos conceitos de país e nação como unidades essencialmente independentes do ponto de vista econômico e comercial. Com as novas tecnologias, a curto prazo o mesmo desafio passará a existir do ponto de vista cultural e da língua. É de se esperar que vários governos não se sintam confortáveis com esse crescente desafio. Talvez seja necessário que o caráter desses governos mude consideravelmente para que os países e nações se adaptem às futuras realidades políticas, sociais e culturais do mundo.

Preocupa, em particular, o processo de transição para o mundo do terceiro milênio, que pode ser traumático. É inevitável que a transição aconteça aos poucos, com cada país decidindo por sua vez se juntar ou não ao bloco dos profundamente 
informatizados. Se a decisão for de não se juntar, resultará a exclusão na certa, e o país passará a fazer parte de um futuro bloco dos excluídos. Se a decisão for por juntar, não há garantia de sucesso na adaptação do país e da nação, internamente e externamente, às novas realidades, pois provavelmente será necessário que uma série de problemas sejam resolvidos a tempo e adequadamente. Naturalmente, o esforço de cada país para juntar-se a um sistema cooperativo global é um tremendo incentivo para que esse sistema dê certo.

O impacto mais imediato das novas tecnologias sobre o desenvolvimento de cada país se dá principalmente pelo uso da tecnologia informática já existente nas mais variadas atividades econômicas, em particular no que diz respeito aos insumos de hardware. Quanto aos insumos de software, o mesmo pode ser dito quanto aos softwares mais básicos de sistema e de operação do hardware, bem como quanto a uma grande quantidade de aplicativos de uso geral. Entretanto, o desenvolvimento de software para aplicações específicas e a adaptação do software existente às condições nacionais são áreas em que faz sentido investir seriamente. Assim, atitudes isolacionistas como as limitações à importação de insumos de hardware, para a proteção de uma única indústria, podem comprometer o desenvolvimento de toda a economia do país.

\subsection{Aspectos jurídicos, legais e regulatórios}

Um aspecto interessante nesse caso é a possibilidade do uso da rede para a administração de muitos setores do governo e de seu relacionamento com o cidadão. Por exemplo, todas as atividades burocráticas que cada cidadão deve executar rotineiramente podem ser realizadas pela rede, com o uso, quando necessário, dos sistemas públicos de criptografia que estão disponíveis, para garantir sigilo, autorização e identificação. Com isso, mesmo processos de autenticação legal podem, em princípio, ser realizados através da rede.

Os aspectos legais associados à rede, tanto no sentido do seu próprio funcionamento quanto do seu impacto em outros setores, são extremamente complexos e, na realidade, quase desconhecidos. A rede nasceu e se desenvolveu como um sistema completamente descentralizado, caótico e anárquico, já se espalhando pelo mundo inteiro, e é extremamente difícil colocá-la, de uma hora para a outra, dentro de um sistema legal organizado e completo. Além disso, atualmente não existem instrumentos efetivos para a imposição de legislação e o policiamento dos participantes.

Tentativas de normatizar o uso da rede e de legislar sobre as atitudes dos participantes, mesmo se apenas no meio acadêmico, têm sido sempre muito limitadas e, mesmo assim, de efeito indefinível. Provavelmente será necessário esperar que primeiro se estabeleça uma considerável jurisprudência para que se possa estabelecer legislação sólida sobre os assuntos da rede.

Certamente o sistema constituído pela rede e pela disponibilidade geral de microcomputadores poderosos tem um grande potencial de impacto em muitos aspectos legais. Por exemplo, existe o desafio ao conceito de copyright, pois o sistema permite o transporte e a cópia de grandes volumes de informação, a custo essencialmente zero, por qualquer usuário. Como será possível defender o sistema de copyright e manter vivo o conceito de propriedade intelectual num ambiente como esse (54)?

Alguns aspectos se relacionam com os mecanismos que os governos e as sociedades que eles representam usam para implementar censura e controle quanto ao conteúdo da informação que é transportada pela rede. Sendo a rede um sistema internacional, quem controlará o que trafega por ela? Poderá o governo de um determinado país emitir leis e implementar decretos que, através da rede, afetarão outros países? De qualquer forma, é extremamente difícil monitorar e policiar toda a informação que trafega na rede, dado o seu grande volume e a volatilidade de sua localização e percurso de transporte. Nesse sentido popularizou-se uma frase atribuída a Rich Saltz:
54 World Intellectual Property Organization (WIPO). http:/ /www.wipo.org/eng/. 
"The net interprets censorship as damage and routes around it".

Uma questão em particular está relacionada com o recente aparecimento de sistemas de criptografia muito eficientes, inquebráveis pela tecnologia atual, que estão se tornando de uso muito comum na rede (55). Os governos em geral, mesmo os democráticos, tendem a assumir que é seu direito ter a capacidade de poder ler qualquer mensagem que seja enviada entre membros de sua população ou para dentro e fora do país. Em alguns lugares, como a França, por exemplo, chega a ser proibida a utilização pela população de qualquer sistema de criptografia. A nova tecnologia da rede põe essa presunção em xeque.

Naturalmente, o desafio é ainda maior para governos autoritários, que insistem em manter suas populações em regime de isolamento em relação ao resto do mundo. Por um lado, a tecnologia da rede está se tornando cada vez mais importante para o desenvolvimento desses países, e por outro é difícil manter uma rede de extensão nacional inteiramente isolada, controlando com rigor o acesso a ela para cada elemento da população, em especial se não se pode contar com a completa boa vontade de cada um dos envolvidos. Como exemplo, podemos citar a tentativa de criação, na China, de uma intranet nacional, ou seja, de uma rede de alcance nacional isolada da Internet.

\section{TENDÊNCIAS ATUAIS DA TECNOLOGIA}

A pesquisa nos mais variados aspectos de computação e telecomunicações é efervescente hoje e deve continuar trazendo novidades no mesmo ritmo frenético a que nos acostumamos. Várias linhas de desenvolvimento vêm sendo anunciadas pela comunidade acadêmica, indústria e Internet Society.

\section{I. Reforma de endereços IP: de 4 para I 6 bites}

Os endereços na Internet são em geral descritos em forma legível como, por exemplo, ime.usp.br. Essa forma é, digamos, temperada para consumo humano. Os endereços "oficiais" adotados pelo protocolo IP são números de 32 bites, normalmente denotados como quatro números entre $0 \mathrm{e}$ 255 (por exemplo, 143.107.45.13). Quando o protocolo foi adotado, 32 bites, que permitem endereçar mais de um bilhão de pontos, eram mais que suficientes. Entretanto, como a alocação de endereços é feita por lotes, observa-se o iminente esgotamento desses endereços.

Para lidar com o grande crescimento da Internet, e com uma série de necessidades técnicas que se tornaram claras com a experiência, uma nova versão do protocolo

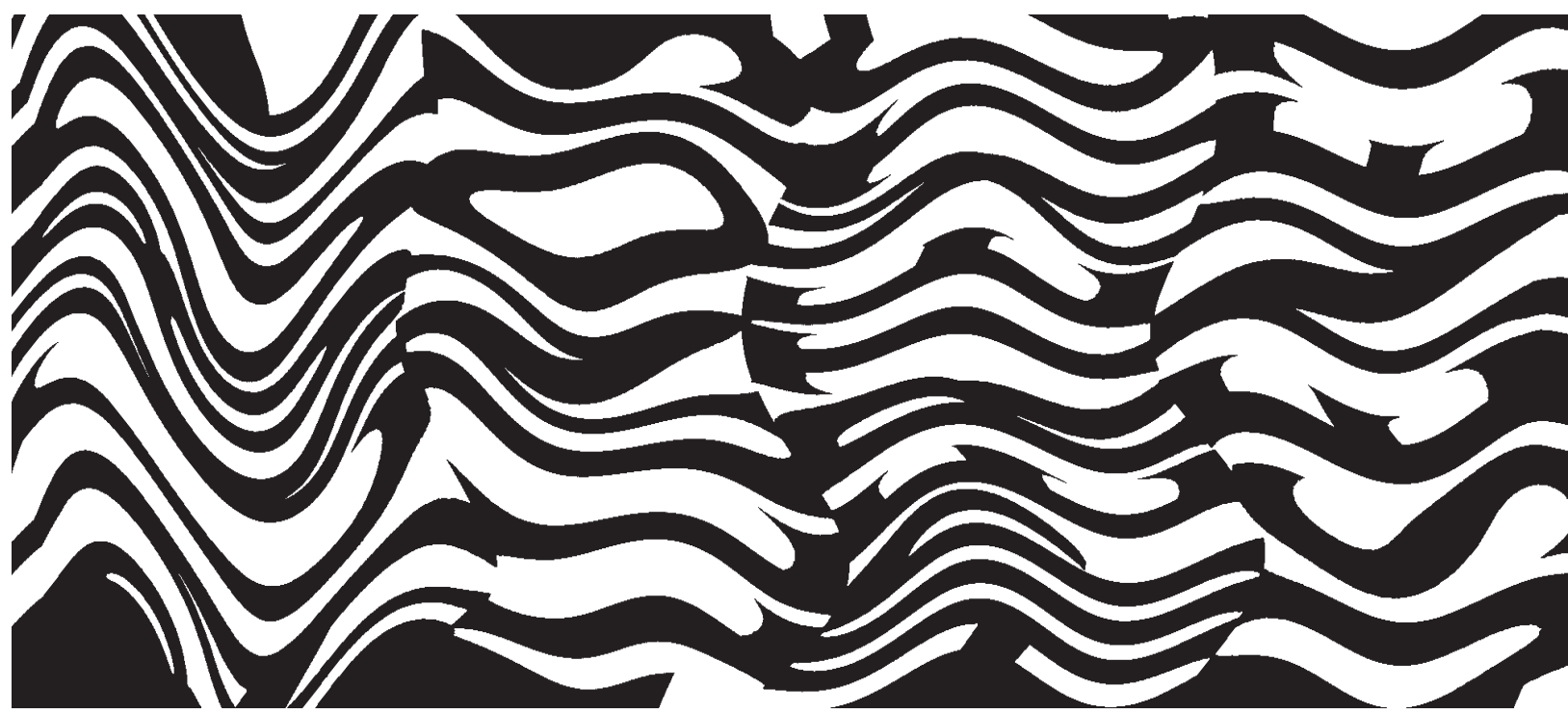


IP foi aprovada, utilizando endereços com 128 bites. A transição do padrão corrente IPv4 ao novo (IPv6) deverá levar dez anos; o IPv6 foi projetado de forma que essa transição possa ser feita suavemente.

Isso parece um aspecto técnico mínimo, mas reflete o amadurecimento da tecnologia de redes: o novo protocolo não só acrescenta características ao anterior, como também retira outras que se revelaram desnecessárias ou que obsolesceram. O IP original contemplava uma rede de uso limitado, militar e acadêmico; o novo tem em vista uma verdadeira rede mundial, com múltiplos usos.

\subsection{Internet II}

Não obstante o seu tremendo êxito como empreendimento, e talvez até por essa mesma razão, a Internet desviou-se muito das suas finalidades originais, tendo chegado a uma situação bastante diferente daquela imaginada por seus idealizadores. De fato, tendo hoje abrangência mundial e estando aberta aos interesses comerciais de todo o planeta, ela não mais pode ser vista como um sistema de comunicações para uso do governo norte-americano e da comunidade de ensino e pesquisa daquele país.

Considerando que a situação atual apresenta vários aspectos insatisfatórios, referentes à eficiência e à capacidade de expansão do sistema e considerando ainda as fortes necessidades de evolução desse complexo, um grupo formado por algumas das principais universidades de pesquisa norte-americanas, por empresas da indústria de informática que desenvolvem tecnologia de ponta e por agências do governo dos Estados Unidos, começou a discutir, há cerca de dezoito meses, o projeto de uma nova rede computacional que vem sendo chamada de Internet II, dotada de novas características e que, em princípio, terá acesso restrito às entidades participantes do empreendimento.

A Internet II, a segunda geração da Internet, está sendo projetada para dotar a comunidade norte-americana de ensino superior e pesquisa de novos modos de colaboração interativa e de ensino a distância, para integrar a distribuição de coleções bibliográficas digitais em forma multimídia com programas acadêmicos e para facilitar o acesso a facilidades de pesquisa especializadas e muito caras, tais como aceleradores de partículas e supercomputadores. Não se destina a substituir a Internet, mas sim a adicionar conectividade ao sistema, com acesso seletivo. O novo sistema estará conectado ao atual e funcionará como uma melhora para finalidades selecionadas. As novas tecnologias empregadas na sua edificação são uma evolução das tecnologias atuais e deverão estabelecer os padrões de uma nova infra-estrutura global de comunicações.

\subsection{Redes totalmente em fibras ópticas}

A fibra óptica já é mais barata e confiável do que o fio de cobre para a transmissão de sinais. Isso está levando à implementação preferencial em fibra de todas as espinhas dorsais de comunicação. Tanto do lado da telefonia quanto da TV a cabo, essa troca ainda não chegou à ponta do consumidor. A principal dificuldade está na instalação de novos equipamentos de chaveamento, e não na instalação dos cabos. Esse problema é econômico, por se tratar de investimento que ou terá um tempo de amortização muito longo ou apresentará uma conta demasiado alta para o consumidor, e que, até agora, não tem suscitado muito interesse das companhias telefônicas. É preciso notar, porém, que o rápido barateamento dos equipamentos, aliado a planejadas mudanças estruturais muito profundas nas empresas de telecomunicações do mundo todo, pode trazer alterações a este cenário a médio prazo.

\subsection{Comunicação versus processamento}

Pelo ritmo de desenvolvimento atual das tecnologias de circuitos e de telecomunicações, o crescimento da velocidade de comunicação tende a ultrapassar de longe 
o crescimento da capacidade de computação. O limite teórico da fibra é de 25 Tbps por fibra, suficiente para que uma só fibra carregue todas as chamadas telefônicas nos EUA no Dia das Mães. Assim, com uma disponibilidade grande de banda, uma série de técnicas, utilizadas atualmente para compactar a informação antes de sua transmissão, deixaria de ser interessante. Curiosamente, a dificuldade maior em aproveitar essa capacidade de comunicação está no processo relativamente lento de transdução entre sinais eletrônicos e ópticos (56).

\subsection{Comunicação sem fio}

Qualquer que venha a ser o sucesso da fibra na construção básica da rede, haverá cada vez mais a necessidade da conexão com a Internet de unidades móveis. Além disso, certas localidades geográficas simplesmente tornam antieconômica a extensão da fibra até elas. Para esses casos é necessário a comunicação sem fio (ou sem fibra) (57). Atualmente isso está sendo implantado com a ampliação dos serviços de telefonia celular e com cada vez maior cobertura do globo por satélites de comunicação.

Em ambos os casos, visa-se a terminais de acesso móveis e com baixa potência. Telefones celulares devem se encaminhar a ponto de se permitir que sejam, efetivamente, pontos de ligação à Internet. Há que se resolver ainda problemas de banda, confiabilidade e segurança de transmissões.

Já está em uso em vários lugares o GPS (Global Positioning System), sistema para a localização precisa, via sinal de satélite, de um veículo em movimento. Isso acoplado a um banco de dados no veículo permite a apresentação ao condutor de um mapa com a posição do automóvel ou barco. É questão de tempo isso se tornar mais comum, com a incorporação de outras informações atualizadas periodicamente via rede, como a existência de congestionamentos, o que permite a elaboração de rotas alternativas.

\subsection{Convergência de meios}

Observando os enormes avanços permitidos pela comunicação digital da informação podemos concluir que haverá uma tendência cada vez mais forte de fusão de várias tecnologias que conhecemos hoje como distintas, tais como telefonia, sistemas de áudio, televisão, computação, redes de computadores e serviços de fax, de secretária eletrônica e de mensageria.

Essa perspectiva pressupõe uma capilarização maciça de redes digitais de uso múltiplo (58). Em primeiro lugar nessa direção vem o advento do modem para cabo, que permite usar a infra-estrutura da TV a cabo para conexão de rede. Alternativamente, a tecnologia B-ISDN (Broadband Integrated Services Digital Network) (59) poderá também levar à capilarização desejada. Existem até pesquisas que pretendem transmitir os sinais da rede Internet através da rede de energia elétrica (60).

Com o uso da rede para transmissão de som os serviços telefônicos usuais deverão ser fortemente afetados.

\subsection{Extensão de aplicações locais à Internet}

Várias aplicações que atualmente só funcionam adequadamente em rede local devem se tornar de uso mais amplo à medida que a capacidade da rede aumentar. Alguns exemplos são diagnóstico médico, jogos interativos em grupo, reuniões virtuais e ensino a distância. Outras aplicações dependem ainda do desenvolvimento adequado de software e protocolos adequados, como, por exemplo, dinheiro eletrônico.

\subsection{Distribuição eletrônica de software}

Desde seu início a rede foi usada para distribuir e desenvolver programas; ao mesmo tempo, o canal preferencial de distribuição foi, e continua sendo, o comércio tradicional. À medida que a banda passante aumentar e mecanismos confiáveis de comercialização eletrônica se solidifica-
60 Adaptive Networks, Inc. http:// www.adaptivenetworks.com/. 
rem, a tendência de distribuição via rede deverá aumentar. Isso tem um aspecto muito mais amplo do que aquilo que normalmente se entende por indústria de software. Atualmente quase todos os equipamentos dotados de eletrônica contêm uma grande quantidade de software; com a possibilidade (futura) de ligarmos a cafeteira ou o automóvel diretamente na rede, esse software poderá ser atualizado remotamente, evitando recalls no caso de falha. Um instrumento recente objetivando essa amplitude de aplicação é a linguagem Java. Seu lançamento foi entusiasticamente acolhido pela indústria e ela deverá ser a base para a primeira geração desse tipo de uso.

\subsection{Trabalho cooperativo em grupo}

Embora esta tenha sido uma das motivações originais de Licklider ao idealizar a rede, e embora a experiência acumulada nessa direção já seja impressionante, há muito espaço e muita necessidade para progresso nessa direção. A concretização de muitas experiências já imaginadas depende ainda de progressos significativos nas áreas de hardware e principalmente de software. As possibilidades chegam a desafiar a mente: ensino a distância, com ênfase na cooperação entre os alunos; serviços de suporte técnico, de treinamento e de desenvolvimento de produtos com a cooperação dos usuários; sistemas de revisão e de comentários públicos sobre trabalhos científicos, sobre livros (61) ou sobre produtos de determinada natureza; sistemas de diagnósticos médicos a distância, com cooperação entre especialistas geograficamente distantes entre si; estabelecimento de bibliotecas digitais especializadas, com a cooperação dos usuários, etc.

As Intranets, em desenvolvimento nos últimos dois anos, e com o pleno uso das tecnologias de comunicação e de cooperação desenvolvidas na Internet, são um exemplo concreto nessa direção, já em andamento (62).

\section{I0. Continuação do processo exponencial}

Tanto pelo lado da computação quanto das telecomunicações há espaço ainda para que o ritmo de crescimento exponencial se mantenha. Conforme já comentamos no fim da subseção 3.10, pelos próximos 15 a 20 anos ainda há espaço para crescimento, cada qual com melhora da ordem de 1.000 vezes da capacidade atual. No caso das pastilhas de silícioé possível que se chegue aos limites físicos dessa tecnologia, mas até lá, provavelmente, novas tecnologias, atualmente nos laboratórios, já estarão viabilizadas (63).

\section{I I. Algumas previsões especulativas}

Enquanto as direções já apontadas podem ser consideradas "previsões seguras", por se referirem a processos já em andamento, outras previsões um pouco mais especulativas podem ser feitas. Isso nos traz à lembrança a frase, atribuída ao grande físico Niels Bohr, "é muito difícil fazer previsões, principalmente sobre o futuro". Aliás, nesse campo as previsões se mostraram quase sempre muito falhas, em geral por excesso de conservadorismo. Tornaram-se folclóricas declarações de capitães da indústria de que "I think there is a world market for maybefive computers" (Thomas Watson, presidente da IBM, 1943, reportado por Time em 15 de julho de 1996) ou "There is no reason for any individual to have a computer in their home" (Kenneth Olsen, presidente e fundador da Digital, 1977, reportado por Newsweek em 27 de janeiro de 1997).

Mesmo no campo altamente especulativo e imaginativo da ficção científica, entre autores que se destacavam por seu alto nível de informação sobre o estado corrente da ciência e tecnologia, encontramos erros hoje risíveis. Por exemplo, Robert Heinlein, em Starman Jones (1953), assume viagens a outros sistemas solares, mas a navegação é feita consultando-se tabelas impressas, cujos valores devem, na medi-
6I Amazon.com Books. http:// www.amazon.com/.

62 R. Bernard, Corporate Intranet, John Wiley \& Sons, Inc., 1996 M. Hills, Intranet as Groupware, New York, John Wiley \& Sons, Inc., 1997 http://www.wiley.com/ compbooks/.

63 D. A. Patterson, "Microprocessors in 2020", in Scientific American, 273 (3) September 1995, pp. 48-51. 
da do necessário, ser digitados no painel. Ou Isaac Asimov que, em The Last Question (1956), descreve um único grande computador que vai sendo aumentado até formar uma camada subterrânea sob todo o planeta. Mesmo entre aqueles que participavam do processo era pouco visível uma idéia clara de onde se chegaria. Na revista Communications of the ACM (Association for Computing Machinery), órgão de divulgação de associação internacional envolvendo tanto a comunidade acadêmica quanto a industrial e empresarial, não se encontra nada, na década de 60 , que pressinta a vertiginosa popularização dos computadores e a idéia de uma rede mundial. Uma notável exceção se encontra em trabalho de Licklider (64), do qual extraímos:

"Economic criteria tend to be dominant in our society. The economic value of information and knowledge is increasing. By the year 2000, information and knowledge may be as important as mobility. We are assuming that the average man of that year may make a capital investment in an 'intermedium' or 'console' - his intellectual Ford or Cadillac-comparable to the investment he makes now in an automobile, or that he will rent one from a public utility that handles information processing as consolidated Edison handles electric power. In business, government, and education, the concept of 'desk' may have changedfrom passive to active: A desk may be primarely a display-and-control station in a telecommunicationtelecomputation system*-and its most vital part may be the cable ('umbilical cord') that connected, via wall socket, into the procognitive utilitynet. Thus our economic assumption is that interaction with information and knowledge will constitute 10 or 20 per cent of the total effort of the society, and the rational economic (or social economic) criterion is that the society be more productive or more effective with procognitive systems than without.

*If a man wishes to get away from it all and think in peaceand quiet, he will have merely to turn off the power. However, it may not
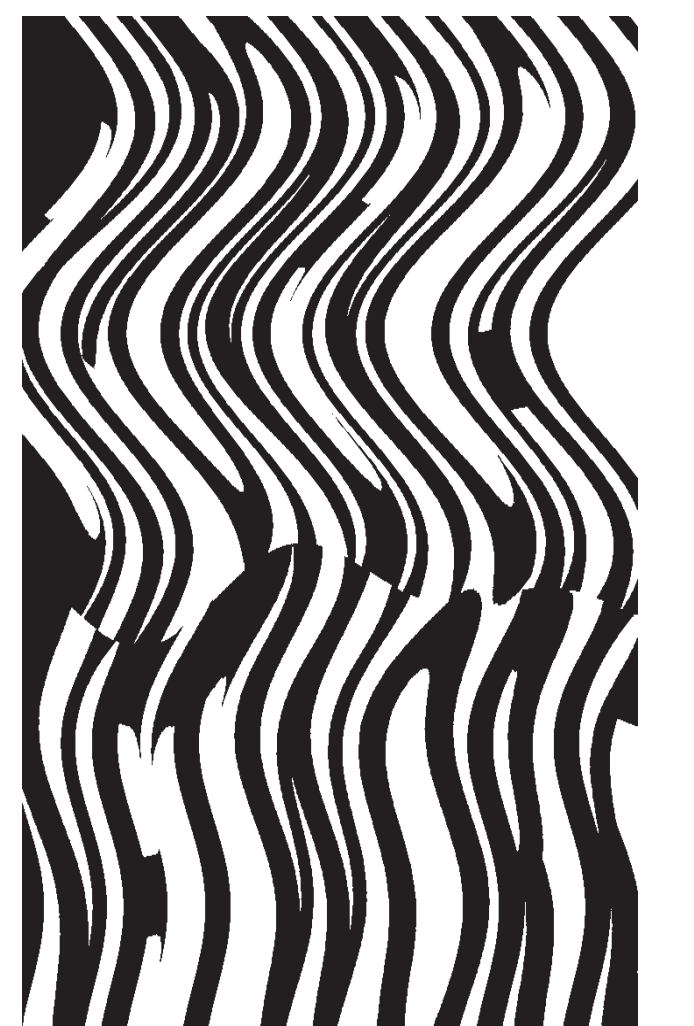

\section{1}

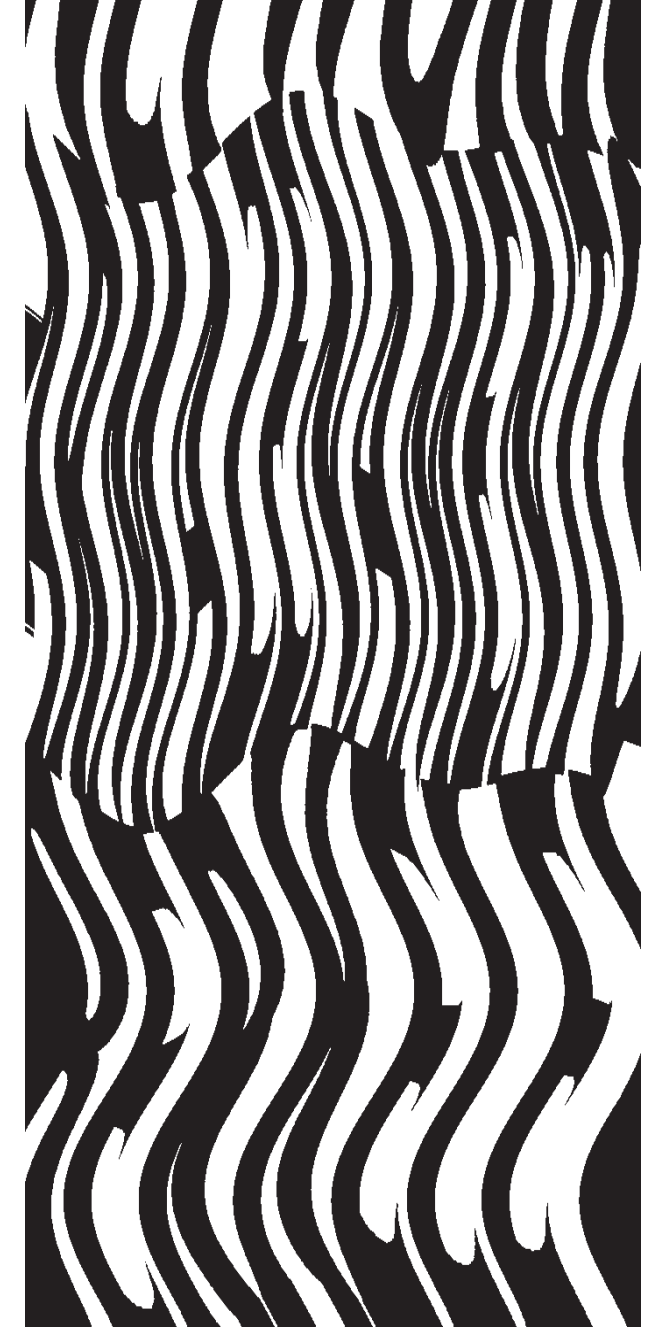


be economicaly feasible for his employer to pay him at full rate for the time he does spend in an unamplified cerebration".

Esse trecho, escrito em 1964, dá uma idéia da extraordinária visão daquele que foi escolhido para idealizar o projeto Arpanet.

Sem maiores pretensões, arriscamos mencionar aqui as seguintes possibilidades:

- Novos paradigmas de computação.

Todos os computadores construídos até hoje têm uma arquitetura baseada num modelo descrito na década de 1940 por John von Neumann. Até o momento, não houve sucesso em nenhum modelo alternativo. A construção de computadores Von Neumann, primeiro em válvulas, e agora em semicondutores, foi bem-sucedida mas esbarra em certas limitações físicas que podem ser eventualmente atingidas, encerrando o processo de crescimento exponencial. São objetos de pesquisa, no presente, modelos diferentes de computação, que deverão ser apoiados em tecnologias hoje inexistentes: computação biológica e computação quântica. Por enquanto, essas duas propostas estão em estado incipiente, tanto pelo lado teórico quanto pelo tecnológico, mas argumentos apriorísticos mostram que, se vingarem, devem aumentar em muito os limites da capacidade de computação.

- "Killer applications".

Esse é o nome dado para as aplicações que conseguem evidenciar a vantagem de uma nova tecnologia, levando à sua adoção maciça. Talvez a convergência com os meios de entretenimento seja já suficiente. Talvez já seja a WWW; foi com os visores gráficos que a Internet se popularizou. Com a oferta crescente de banda e capacidade de computação, é muito provável que novas aplicações surjam com esse efeito catalisador. Já citamos algumas em vista; dessas, a implementação efetiva de dinheiro eletrônico é candidata a ter um impacto mais visível, afetando profundamente as bases do sistema econômico.

- Massificação total.
Já é recomendada pela IEEE a colocação de tomadas de rede à base de uma para cada $5 \mathrm{~m}^{2}$ numa área de trabalho. Prédios modernos de escritórios já estão sendo construídos com uma tomada de rede ao lado de cada tomada elétrica comum. Com o tempo isso deve chegar aos lares, a rede de comunicação se tornando algo tão comum e essencial à vida moderna quanto a energia elétrica: possivelmente, num futuro não muito distante, cada eletrodoméstico será ligado a ambas as redes. Ou, talvez, bastará ligá-los apenas à rede de energia elétrica (65). Com novas interfaces homemcomputador ora em desenvolvimento, cada indivíduo carregará permanentemente seu próprio instrumento de acesso, seja diretamente acoplado ao corpo, seja como parte do vestuário.

Para outras previsões especulativas nos restringimos a encaminhar o leitor interessado para a conferência ACM 97, realizada em San Jose, CA, entre 3 e 5 de março de 1997. A conferência foi o ponto culminante das comemorações dos 50 anos de existência da associação e foi dedicada ao tema "The Next 50 Years of Computing”. Alguns dos especialistas mais formidáveis da área deram os seus depoimentos que foram publicados em livro (66). Alguns números recentes da Communications of the ACM trazem entrevistas com alguns dos palestrantes (67).

\section{EPÍLOGO}

Quais os limites da revolução da informação? Não existe nenhum à vista. $\mathrm{O}$ que se pode ver é que praticamente nenhuma atividade humana sairá incólume da revolução da informática, que promete chegar ao seu ápice ao amanhecer do terceiro milênio. A rede Internet e o sistema WWW estão tomando o mundo de assalto, depois de uma incursão preliminar muito profunda, se menos barulhenta, do exército dos microcomputadores. A combinação desses dois exércitos invasores é potencialmente explosiva. Senhores acadêmicos, por mais azul que o céu lhes pareça, apertem os seus cintos!

\footnotetext{
65 Adaptive Networks, Inc. http:// muw.adaptivenetworks.com/.

66 P. J. Denning and J. M. Metcalfe (eds.), Beyond Calculation: The Next 50 Years of Computing, Copernicus Books (Springer-Verlag). 1997.

67 Maiores informaç̃̃es podem ser encontradas em: The ACM97 Conference. http:// www.acm.org/acm97.
} 